\title{
The Acoustic Streamflow-Measuring System on the Columbia River at The Dalles, Oregon
}

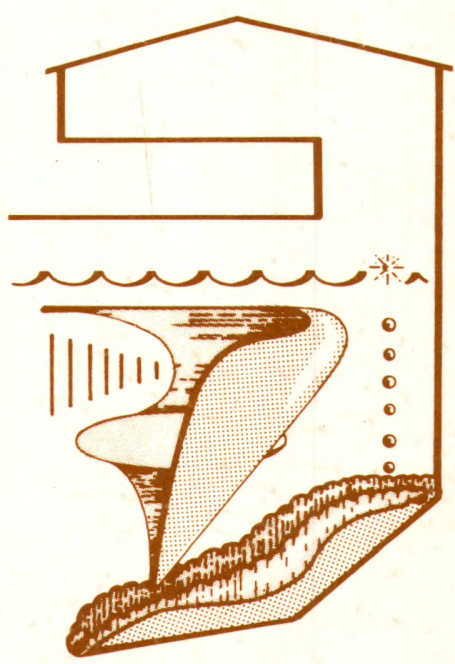




\section{The Acoustic Streamflow-Measuring System on the Columbia River at The Dalles, Oregon}

By

Winchell Smith, Larry L. Hubbard, Antonius Laenen

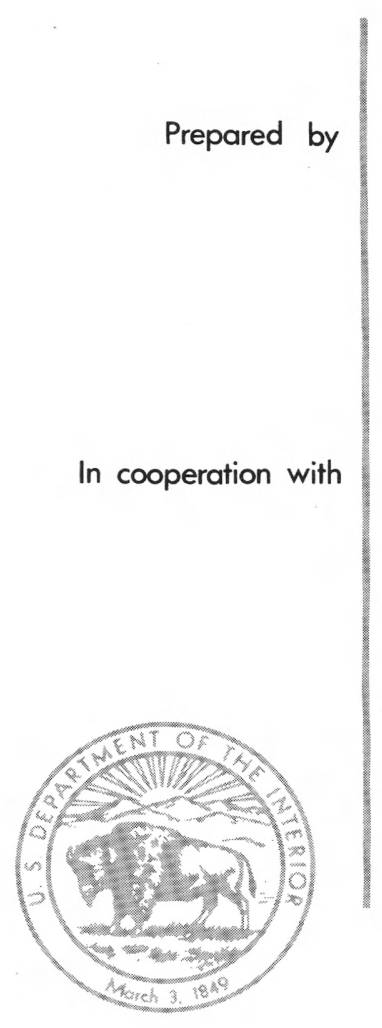

UNITED STATES DEPARTMENT OF THE INTERIOR

Geological Survey

Water Resources Division

Portland, Oregon

U. S. Army Corps of Engineers

Bonneville Power Administration

U. S. Bureau of Reclamation

Open-File Report. . . January 1971 


\section{CONTENTS}

Page

Abstract-1-0 1

Introduction-

Purpose and scope-1 3

Acknowledgments

Description of the gaging station- 5

General details 5

The stream-gaging problem- 8

Methods of determining discharge-1. 8

Problems at The Dalles site-1 9

Line-velocity index concept-12

The acoustic velocity meter 15

Total traveltime circuit- 17

Sing-around circuit- 18

Differential-time circuit-_. 19

Signal-detection methods-an 21

The acoustic streamflow-measuring system at The Dalles-_...-... 24

Layout of equipment 30

Data output 30

Internal system operation- 34

History of installation- 35 
Calibration of the system-1

Calibration equations

Definition of the relation between stage and area-... 39

Definition of the relation between stage and index-mean velocity coefficient-1... 39

Computation of daily discharge- 42

Accuracy of discharge records- 44

Costs of the AVM system at The Dalles. 47

Design considerations for AVM installations- 48

Centra1 processor

Communication 1ink- 49

The acoustic subsystem- 49

Relation between resolution error and path orientation--- 49

Effects of variation in streamline orientation-... 50

Vertical location of acoustic path- 53

Acoustic-signal propagation- 53

Refraction of acoustic signals- 53

Attenuation of acoustic signals- 55

Placement of the acoustic path- 57

Summary and conclusions- 58

References cited-1 59 
Figure 1. Profile of the Columbia River from mouth to Canadian border-.... 4

2. Map showing stream-gaging site, Columbia River at The Dalles, Oreg

3. Map of cross sections showing configuration of the Columbia River at The Dalles, Oreg., stream-gaging

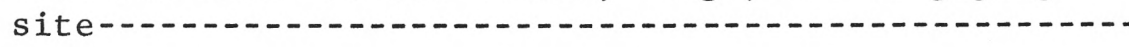

4. Plot of cross section at The Dalles, Oreg., showing changes from 1932 to 1969

5. Curve showing typical free-fall stage-discharge relation for Columbia River at The Dalles, Oreg-...

6. Plot of current-meter measurements after development of backwater from Bonneville Dam, and comparison with free-fall stage-discharge relation--..-..-

7. Curves showing stage-fall-discharge relation for

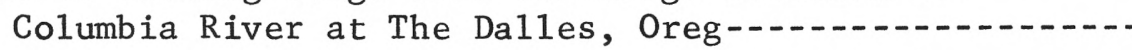

8. Curve showing AVM calibration at Delta-Mendota Canal near Tracy, Calif-..

9. Curve showing variation of ratio $\bar{V} /\left(V_{L}\right)_{5.6}$ with stage in Delta-Mendota Canal near Tracy, Calif-.......... 14

10. Curve showing comparison between $V_{L}$, recorded by the AVM, and $\bar{V}$, computed from gaging-station records, Snake River near Clarkston, Wash----------

11. Sketch to illustrate operating principles of the AVM---- 17

12. Reproduction of oscilloscope trace of acoustic wave received at the near side of the AVM system at The Dalles, Oreg-...

13. Reproduction of expanded oscilloscope trace of the acoustic wave as shaped by amplification and the trigger pulse for the AVM system at The Dalles, Oreg--

14. Reproduction of oscilloscope trace of acoustic wave received at the far side and transmitted over 4,500 feet of line to the central processor of the AVM system at The Dalles, Oreg... 
Figure 15. Sketch showing layout of AVM system-a 24

16. Artist's sketch of structures at The Da11es, Oreg---- 25

17. Block diagram of AVM system-... 26

18. Photograph of transducer-an 27

19. Plot of river cross section along the acoustic path at The Dalles, Oreg., site-... 28

20. Photograph of central console-1 29

21. Photograph of secondary console-... 30

22. Sketch of physical arrangement of equipment in 10by 12-foot primary shelter at The Dalles, Oreg--.-- 31

23. Copy of printout from AVM system- 32

24. Block diagram of output system- 33

25. Curve showing stage-area relation-- 40

26. Curve showing relation between project discharge and discharge from current-meter measurements-.....-. 41

27. Curve showing relation between stage and index-mean velocity coefficient for the AVM system with transducers located at 38-foot elevation-... 43

28. Computer printout of discharge- 45

29. Hydrograph of daily AVM discharges and graph of percentage deviation from adjusted project discharges, April 22-September 30, 1969-.... 46

30. Sketch illustrating possible variation in streamline orientation-... 51

31. Curves used as preliminary guide for AVM site selection (refraction consideration only)-.-.- 54

32. Curves showing attenuation of acoustic signal caused by suspended-sediment load-_.-. 56 
Table 1. Duration statistics for suspended sediment on

Columbia River at Vancouver, Wash- 8

2. Cost of the AVM system at The Dalles, Oreg-_...... 47

3. Annual operation and maintenance costs-- 48

4. Variation of resolution error with path orientation

for a given AVM system-.. 50

5. Variation of the ratio $\frac{\mathrm{Q}_{\mathrm{AVM}}^{\prime}}{\mathrm{Q}^{\prime}}$ with $\emptyset \ldots 52$ 


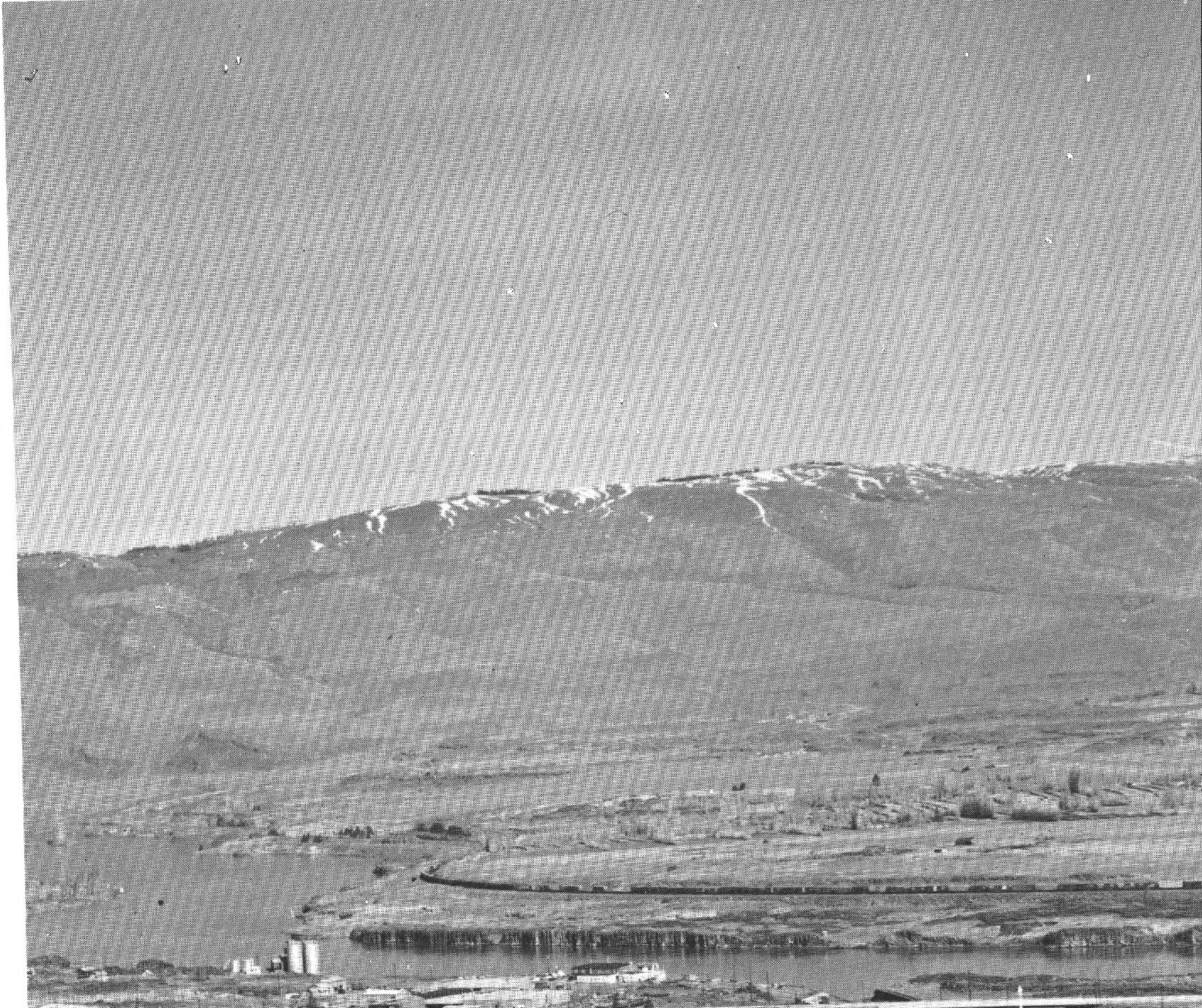

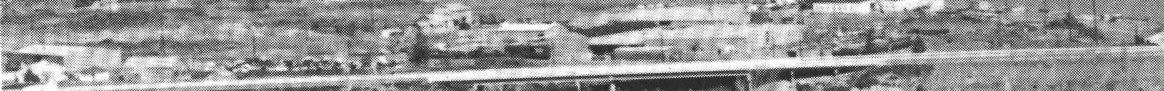
-

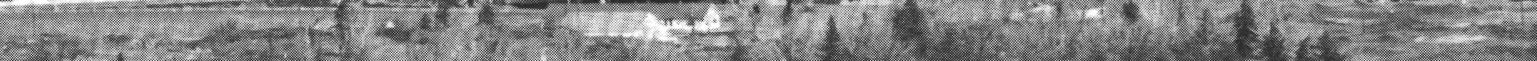

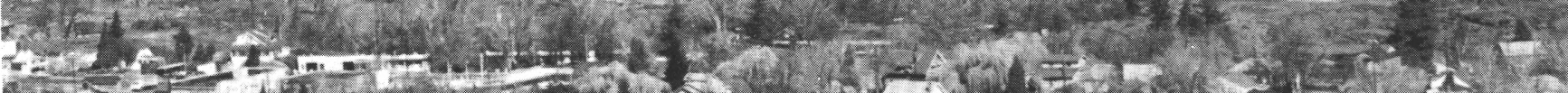

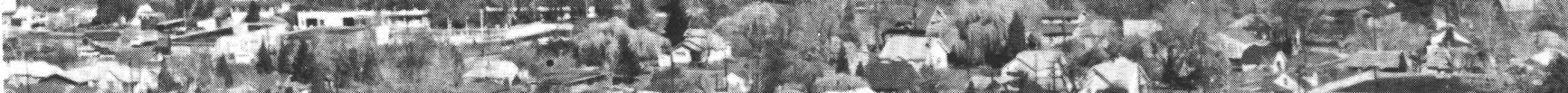
Tin

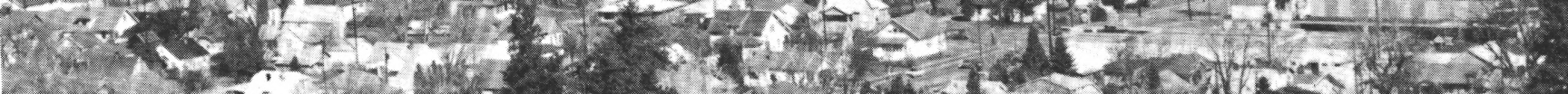

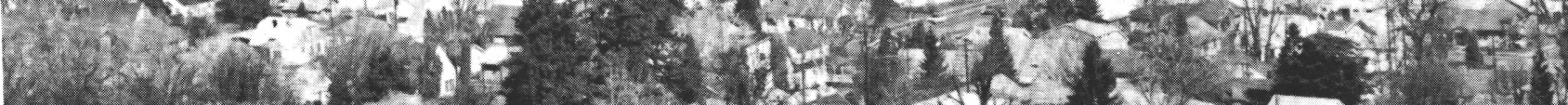

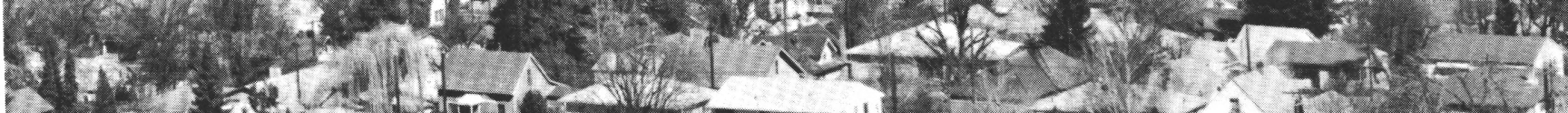

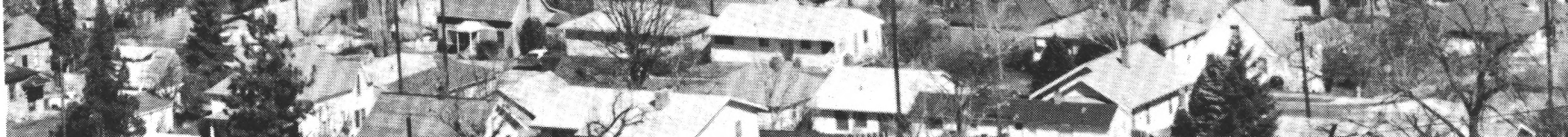

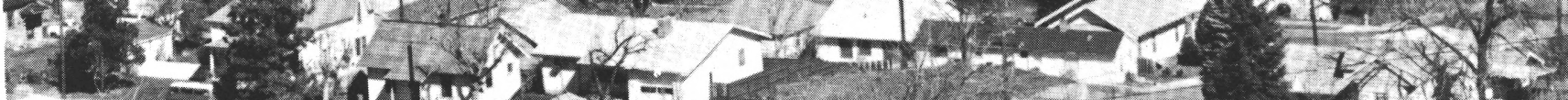

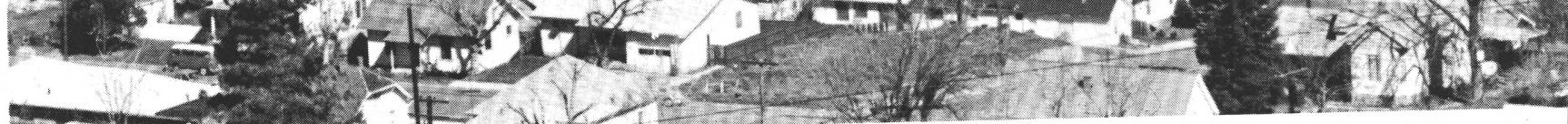




\title{
The Acoustic Streamflow-Measuring System on the Columbia River at The Dalles, Oregon
}

\author{
By Winche11 Smith, Larry L. Hubbard, and Antonius Laenen
}

\begin{abstract}
Records of discharge on the Columbia River at The Dalles, Oreg., are vital to the management of the complex water-development projects in the Columbia River basin. Accurate discharge figures are needed for consistent day-to-day management and are required to meet treaty obligations with Canada.

Because dams have been erected that completely control watersurface elevations at nearly all points in the river from Bonneville Dam to the Canadian border, conventional stream-gaging methods, used historical1y, are no longer adequate. Consequently, new techniques must be used to obtain the accurate discharge records required--records that are computed independently from the hydroelectric operation 1 ogs and that stand alone as the recognized flow records in the basin.

This need for an accurate, independent gaging system has been met by the installation of an acoustic streamflow-measuring system in the river channel at The Dalles, Oreg. This device provides an index of water velocity by measuring the difference in traveltimes of acoustic pulses transmitted through the water in each direction along a diagonal path across the river. The flow of water along the path increases the speed of one signal and retards the speed of the other. The difference in time of travel is related linearly to the water velocity along the path. The velocity index and river stage are used as a two-variable index in the computation of flow. These variables, correlated against current-meter measurements made with specialized boat equipment, provide a reliable basis for computations of instantaneous and daily mean discharges.
\end{abstract}


Installation of this sytem, which is the first application of an AVM (acoustic velocity meter) in a large natural channel, was completed in April 1969. It has been in continuous operation since that date. Performance has been satisfactory, and similar installations at other key points in the Columbia River basin are now under consideration. This paper covers the general theory behind acoustic velocity meters, tracing development from earlier concepts to the present commercially available system. Conclusions are that the AVM can now be considered as an operational instrument which permits accurate gaging of river discharge at many sites where conventional stream-gaging procedures have proved to be unreliable.

\section{INTRODUCTION}

The Columbia River is the third largest river in terms of flow in the United States (U.S. Geo1. Survey Circ. 44) and is the largest producer of hydroelectric power. The mean annual flow of the river at The Dalles, 189 miles upstream from the mouth, is 194,000 cfs (cubic feet per second), and floodflows exceeded 1 million cfs in 1894 and 1948 . Flows at this point represent the runoff from 237,000 square miles of drainage regulated by the upstream multiple-use dams. Streamflow records are required by international treaty obligations with Canada for the joint development of the river; they also serve as an important adjunct to the management of this resource, which is so vital to the economy of the whole Northwest.

The importance of streamflow data for the Columbia River in the vicinity of The Dalles was realized as early as 1858, when the Oregon Steam Navigation Co. recorded peak-stage data at Lower Cascade Landing. Record collection was begun in 1878, and continuous records of daily discharge have been published by the U.S. Geological Survey since that date.

Before extensive developments were made for power and irrigation, techniques required for gaging of the river were relatively straightforward. Early measurements at The Dalles were made by boat. Velocity profiles in the vertical were defined and subsequent measurements were computed on the basis of velocity observations at a fixed depth below or at the water surface. The river channel was fairly stable, and exce1lent correlation between observed stage and measured discharge was possible.

The history of gaging the Columbia at this site has been colorful. Two large cableways erected to permit current-meter measuring during all conditions of flow were destroyed during the period of record. The first cableway at the present gaging site was struck by a steamboat in June 1933. The second structure, located upstream above Celilo Fa11s, was a clear span of 1,727 feet erected on 100-foot towers and was accidentally pulled down in 1951 by the boom of a passing river dredge. In 1948 , Geological Survey hydrographers had measured a flow of 1.0 million cfs from this cableway. 
Stream-gaging problems in the river began to change in 1933 after the construction of Rock Island Dam. Today, the 50-mile reach below Priest Rapids Dam is the only free-flowing natural reach of channel in the river from Bonneville Dam to the international border. The entire reach downstream from Bonneville Dam to the mouth is affected by variable backwater from ocean tides. No other site is suited for accurate stream gaging by the conventional techniques described by Carter and Davidian (1965). Backwater behind each of the stairstepped projects extends to the toe of the dam next upstream. This is graphically portrayed in figure 1 , which delineates developments on the river as of April 1970.

Coincident with this development has been the need for streamflow records of even better accuracy. The stream-gaging problem has become much more complex, and the search for new and better tools led to the development of the acoustic velocity-metering system, which is the subject of this paper.

\section{$\underline{\text { Purpose and Scope }}$}

Problems associated with accurate gaging of riverflows in channels affected by variable backwater from tidal action or from manmade structures have resulted in intensive efforts to develop new techniques and equipment. The AVM (acoustic velocity meter) is a device that has been extensively researched by the Geological Survey and others and represents a significant advance in stream-gaging technology. The AVM on the Columbia River at The Dalles is the first installation of such equipment on a large river channel. This report has been prepared to describe this acoustic velocity-metering system, to outline the reasons for selection of this type of equipment, to document the performance of this system, and to provide technical information for use in future decisions on the application of such a system.

\section{Acknowledgments}

Preparation of this report was a joint effort between the California and Oregon Districts of the Water Resources Division of the U.S. Geological Survey. Work was performed under the direction of $R$. Stanley Lord and Stanley F. Kapustka, respective district chiefs in California and Oregon. The system was financed jointly by the U.S. Army Corps of Engineers, the Bonneville Power Administration, and the U.S. Bureau of Reclamation.

Many individuals have contributed to the success of the AVM project. Special acknowledgment is extended here for the guidance and encouragement furnished by Mark Nelson and Gordon Green of the Corps of Engineers and Fred Limpert of the Bonneville Power Administration, and to R. B. Sanderson, R. W. Childreth, and W. A. Hart of the Geological Survey, Portland, Oreg., who were primarily responsible for the complex and difficult installation at the site. 


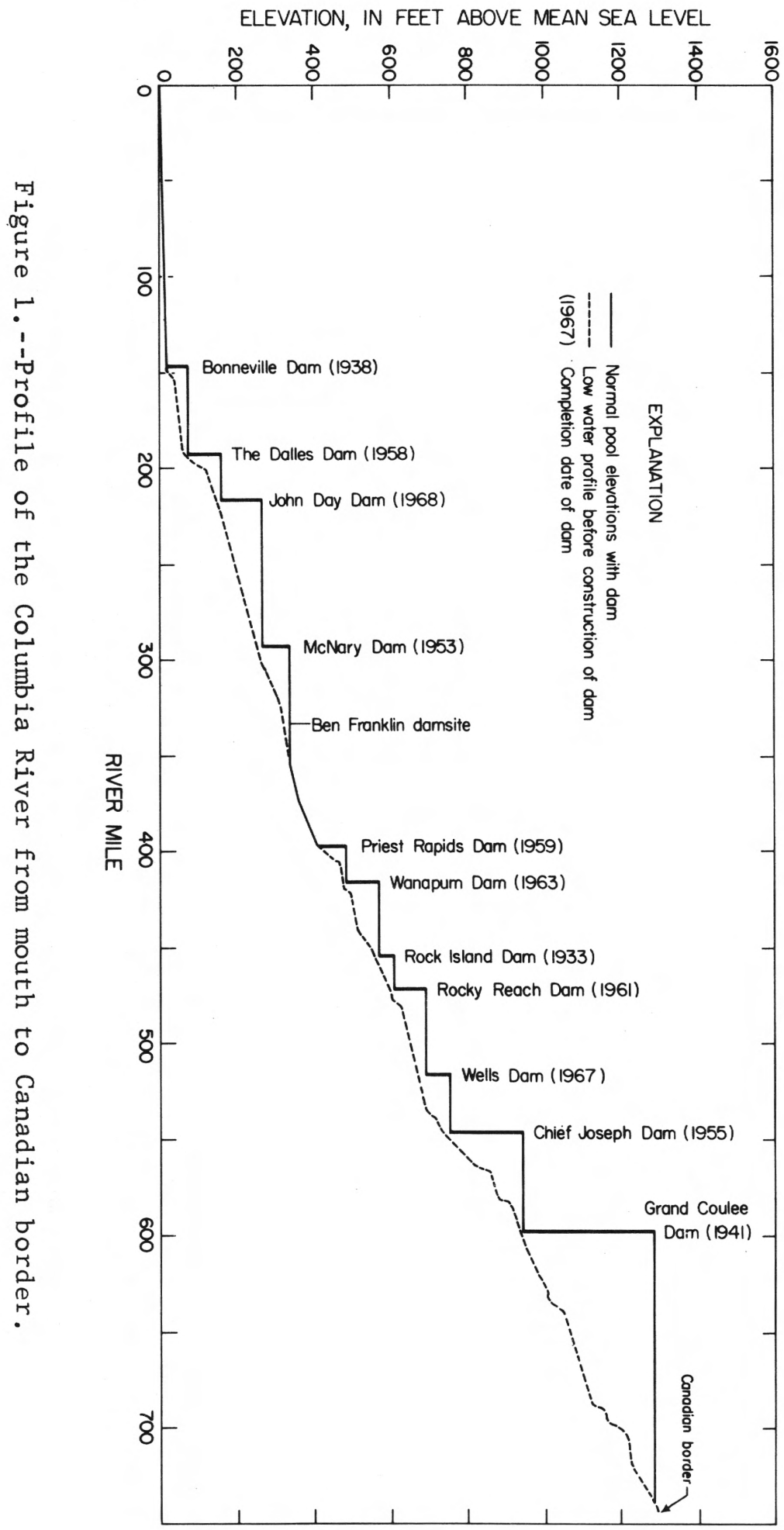




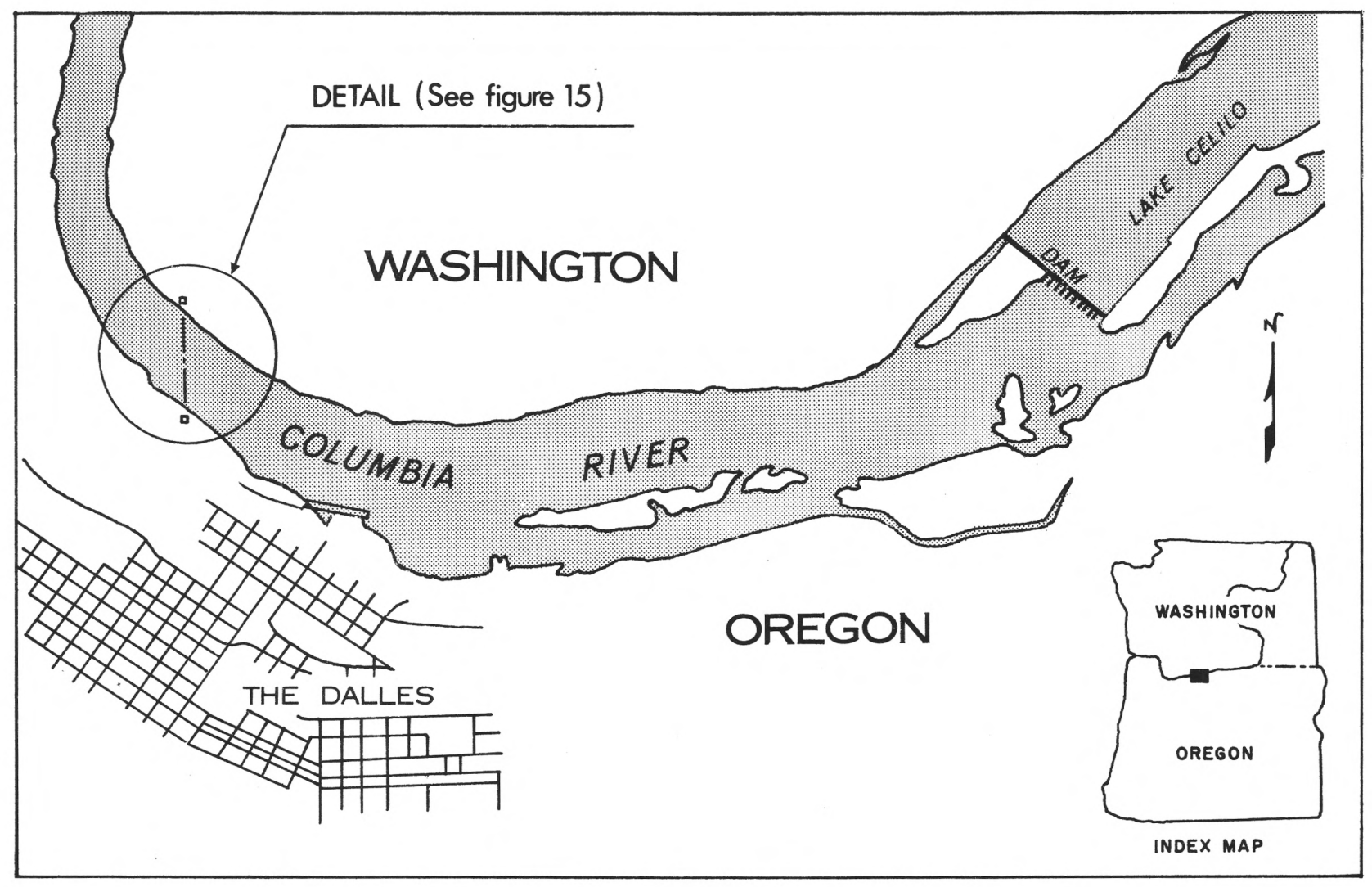

Figure 2.--Stream-gaging site, Columbia River at The Dalles, Oreg.

\section{DESCRIPTION OF THE GAGING STATION}

\section{General Details}

The gaging site on Columbia River at The Dalles, Oreg. (figs. 2 and 3 ) is at the head of the Columbia Gorge where the river begins its passage through the Cascade Range. This is an area that has temperature extremes ranging from $-30^{\circ}$ to $115^{\circ} \mathrm{F}$. Rainfall is $10 \mathrm{w}$, averaging about 14 inches, and winter snowfall averages about 24 inches. The climate is significantly modified by the dominant westerly winds that funnel through the Columbia Gorge, reaching recorded maximums of 57 miles per hour with gusts as high as 88 miles per hour. These winds cause an upstream migration of waves and seriously complicate the stream-gaging problem.

At this site the channel is deeply incised into the basalt. The measuring section is about 1,150 feet wide and roughly trapezoidal, with a maximum depth of about 120 feet. Flow is northwestward through the contracting section. Figure 3 shows the channel configuration from about 2,000 feet upstream from the station to about 2,000 feet downstream. Changes in bed elevation of as much as 30 feet occurred in this channel during significant flood events prior to the construction of 


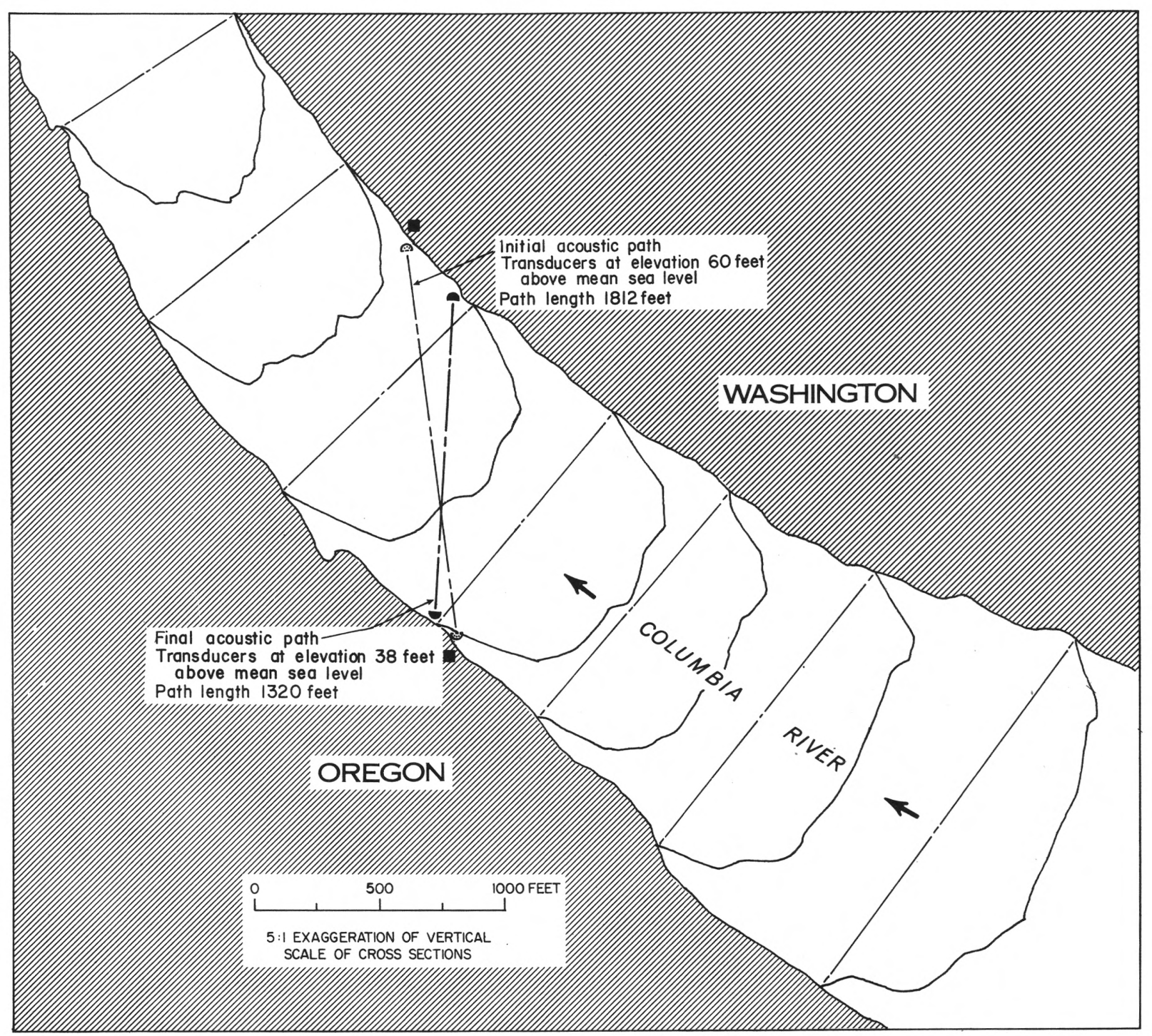

Figure 3.--Cross sections showing configuration of the Columbia River at The Dalles, Oreg., stream-gaging site.

major dams on the river. However, conditions have stabilized since completion of The Dalles project. This is illustrated in cross-sectional plots showing the channel geometry in 1932, 1963, and 1969 (fig. 4). Further changes in geometry will be slow because the bulk of erodable material has already been carried out of the section and the incoming supply of heavy sediment is being trapped in reservoirs above the station.

Discharges at The Dalles during the 90-year period of observation have ranged from $1,240,000$ cfs on June 6,1894 , to 35,000 cfs on January 12,1937 . The average annual mean over this period of record is $194,000 \mathrm{cfs}$. Suspended-sediment load is generally 1 ess than $20 \mathrm{mg} / 1$ (milligrams per liter), but there are times in most years when concentrations exceed $150 \mathrm{mg} / 1$. The probable period of record maximum, estimated on the basis of observations at Vancouver, Wash., was about 


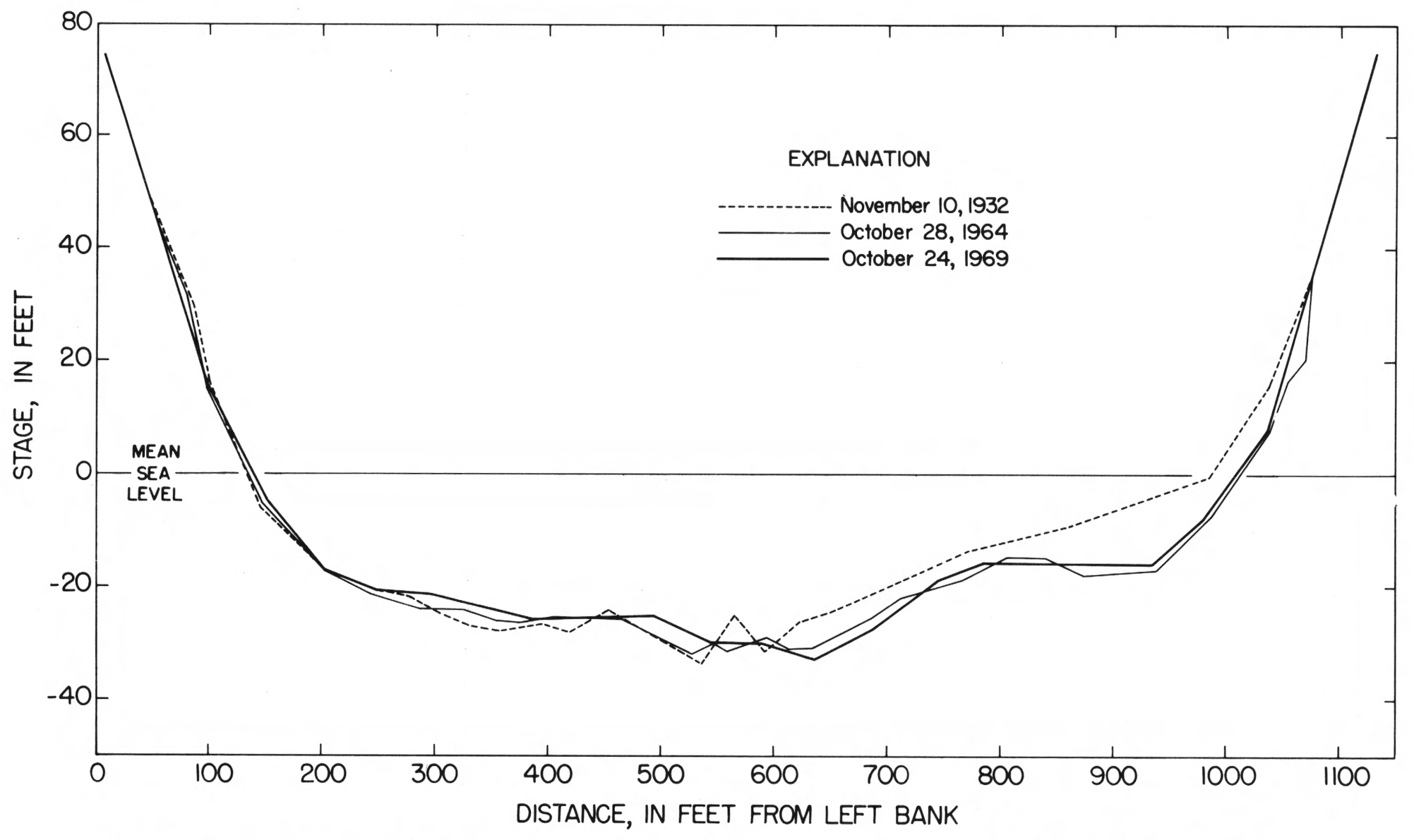

Figure 4.--Cross section at The Dalles, Oreg., showing changes from 1932 to 1969. 
3,600 mg/1 during the December 1964 flood. Table 1 below shows the duration statistics for sediment discharges observed on Columbia River at Vancouver, Wash.

Table 1.--Duration statistics for suspended sediment on Columbia River at Vancouver, Wash. 17

\begin{tabular}{cc}
\hline $\begin{array}{c}\text { Suspended sediment } \\
\text { concentration } \\
(\mathrm{mg} / 1)\end{array}$ & $\begin{array}{c}\text { Percentage of time } \\
\text { concentration is } \\
\text { exceeded }\end{array}$ \\
\hline 2,000 & 0.05 \\
1,000 & .11 \\
500 & 1.9 \\
200 & 8.7 \\
100 & 18 \\
50 & 38 \\
\hline
\end{tabular}

1/ Data from U.S. Geologica1 Survey gaging station.

The Stream-Gaging Problem

Methods of Determining Discharge

General procedures for gaging riverflows are described by Carter and Davidian (1968). The most straightforward procedure applicable to open stream channels of appreciable slope depends on the empirical definition of a relation between water-surface elevation or stage and discharge. A continuous record of stage is obtained by installing instruments that sense and record the water-surface elevation in the stream. Discharge measurements, such as described by Buchanan and Somers (1969), are initially made at various stages to define the relation between stage and discharge. This stage-discharge relation is then checked by subsequent periodic current-meter measurements to verify its stability or to define changes resulting from any modification of channel geometry. Computations of instantaneous and average daily discharges are made by application of the stage-discharge relation of the recorded continuous record of stage。 
At sites affected by variable backwater or in reaches of extremely low slope, a unique relation between stage and discharge cannot be established, and variables other than stage must be continuously recorded to obtain the discharge record. These variables may include the watersurface slope defined by stage gages at each end of a reach. Computations of discharge are then based on stage, slope, and rate of change of stage in the measuring reach. Where these techniques fail, dependence must be placed on alternative procedures such as computation of flows through hydraulic structures, which may be very complex as are the major structures on the Columbia River, or on the routing of flows from reliable records at other points in the river system.

\section{Problems at The Dalles Site}

Each of these techniques has been employed in the determination of flow at gaging stations on the Columbia River in the vicinj.ty of The Dalles. Simple stage-discharge relations such as those shown in figure 5 were used from June 1878 through March 15, 1957. The relation shown is for the present site before the construction of Bonneville Dam and demonstrates the relative stability of the channel and section control. Excellent discharge records were obtained during this period. Following construction of Bonneville Dam, the gage was moved upstream above Celilo Falls, where another simple stage-discharge relation was used

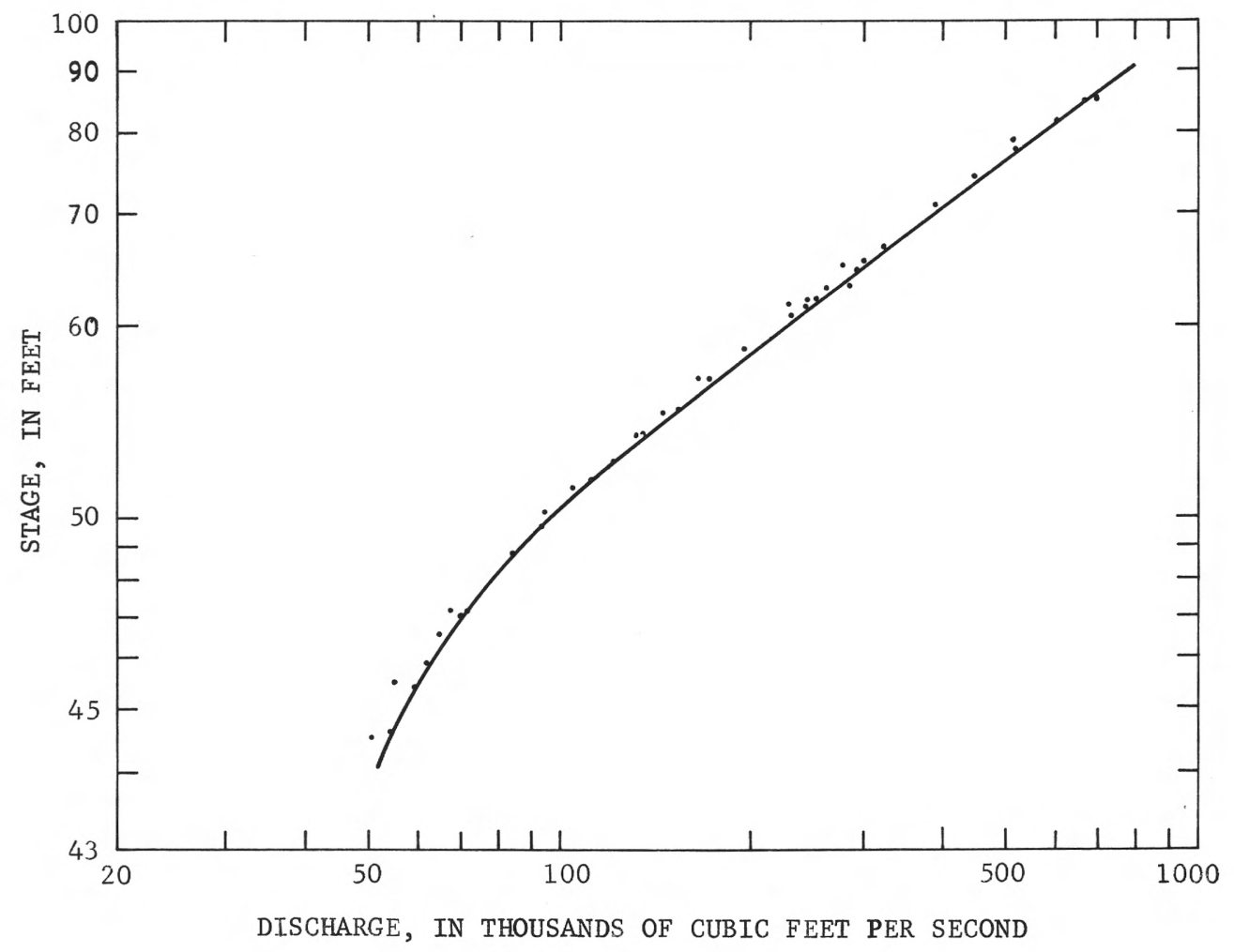

Figure 5.--Typical free-fall stage-discharge relation for Columbia River at The Dalles, Oreg. 
until March 1957 when that site also was inundated by the newly constructed The Dalles Dam. At that time, the gage was relocated to its previous site at the upper end of the Bonneville pool. This reach is affected by backwater from Bonneville Dam as illustrated in figure 6, which shows measurements plotted to the free-fall rating for the same reach. As can be seen from this plot, a simple stage-discharge relation could not be established at this site, and it was necessary to develop the stage-fall-discharge relation shown in figure 7 by using stage records at The Dalles and at Hood River Bridge 19 miles downstream。

A stage-fall-discharge relation such as that in figure 7 does not correct for the changes in momentum and kinetic energy resulting from dynamic-flow changes. Hence, instantaneous discharges during periods of nonsteady flow cannot be computed. Flow below The Dalles Dam is responsive to regulation from both The Dalles project and the Bonneville project. Operation of these plants to meet daily peak power demands results in nonsteady flow conditions in the river during a significant part of each day. Analysis of discharge figures computed from the stage-fall-discharge relation indicate that mean daily discharges have been within generally accepted limits of accuracy, but that instantaneous discharges have been frequently in error. It was also found that the fall, sometimes as 1 ittle as 0.2 foot in the 19 -mile reach, could not be measured with sufficient accuracy to reliably define discharges of less than 300,000 cfs.

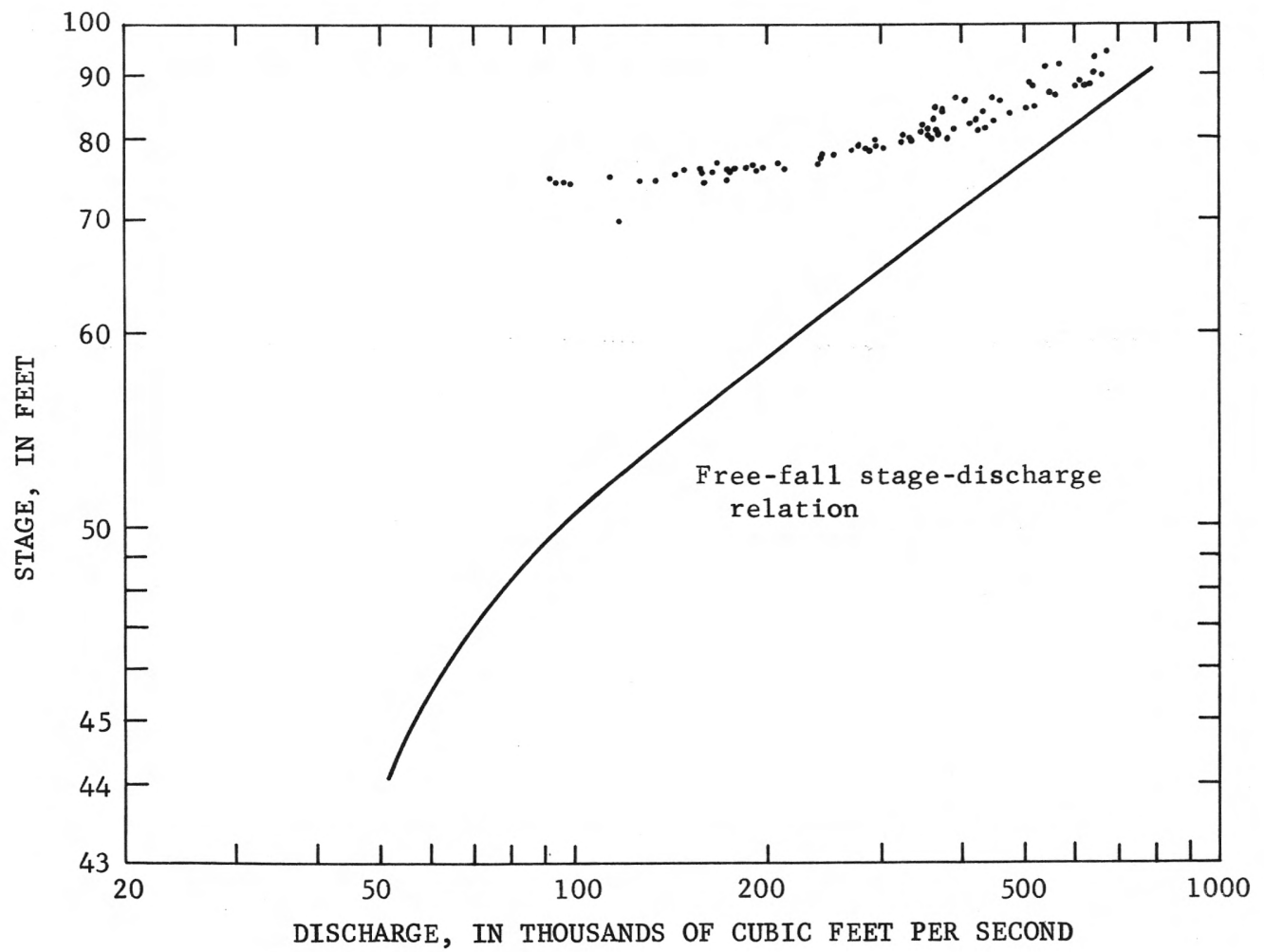

Figure 6.--Current-meter measurements after development of backwater from Bonneville Dam, and comparison with free-fall stage-discharge relation. 


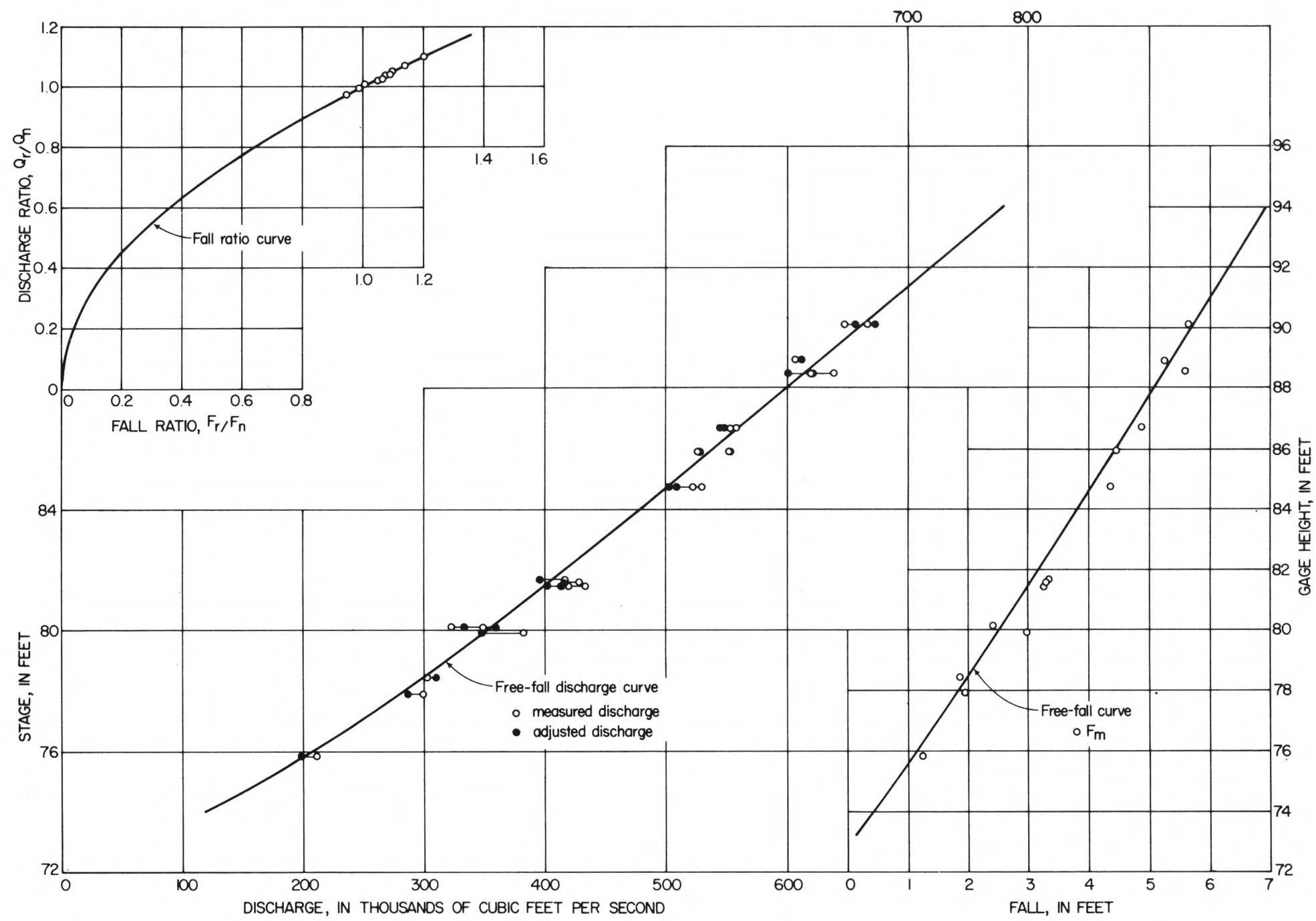

Figure 7.--Stage-fall-discharge relation for Columbia River at The Dalles, Oreg. 
Insensitivity of the stage-fall computation procedures required that discharges during several months of each year be computed by routing of the flows gaged below McNary Dam, 103 miles upstream, or by computations of flows through The Dalles project. Close agreement was obtained between project figures at The Dalles Dam and independent current-meter measurements for periods when all the flow passed through the turbines, which were carefully rated by the U.S. Army Corps of Engineers. However, when part of the discharge passed over the spil1ways, a departure of about 5 percent was found for flows above 200,000 cfs. Routed figures may be subjectively biased by the many assumptions basic to the routing equation; consequently, such records are open to question. At best, they demonstrate that discharge figures in the river system are consistent with one another. Routed discharge figures cannot be considered as actual records of flow.

In summary, conventional stream-gaging techniques can no longer be utilized for accurate flow computations at The Dalles site, nor will the alternatives available provide the independent reliability of records needed at this key site in the Columbia River basin. A different system, unaffected by variable backwater conditions, is needed. Utilization of a technique that will yield an accurate measure of the velocity in the channel seems to be the most practical solution. At this time, the AVM system is the best device for recording this parameter.

\section{LINE-VELOCITY INDEX CONCEPT}

The ideal velocity meter would be a device that could record a spatial integration of velocities over the entire cross section of a stream; however, present technology has not developed an economical method for obtaining this integration. Approaches such as the insertion of grids of rotating current meters in penstocks and small channels have been costly and cannot be considered applicable to a continuous openchannel measuring system. As an alternative, the concept of a velocity index has been investigated. Experimental work by Miller (1962) and Craig (1963) showed that a record of the velocity at a single point in a stream cross section could be used as an index of variations in the mean velocity in that section if current-meter measurements were obtained to define the empirical relation involved. Accuracies obtainable by use of a point-velocity index are controlled by the stability of the flow regime at the site and the extent to which observed velocity variations are typical of variations in the mean velocity in the cross section. A corollary conclusion to be drawn from evaluations of the significance of point-velocity indexes is that a record of the average velocity along a horizontal line spanning the major part of a channel should be a very stable index of the mean velocity in the cross section. This led to the conception of an acoustic-metering system that could record the average stream velocity along a path diagonal to the streamlines of flow, an index velocity referred to hereafter as a line velocity.

Data on the stability of the relation between a line velocity and the mean velocity in a cross section were collected at two open-channel sites, the Delta-Mendota Canal near Tracy, Calif., and the Snake River near Clarkston, Wash., by Smith and Wires (1967) during the course of development work on an AVM. 


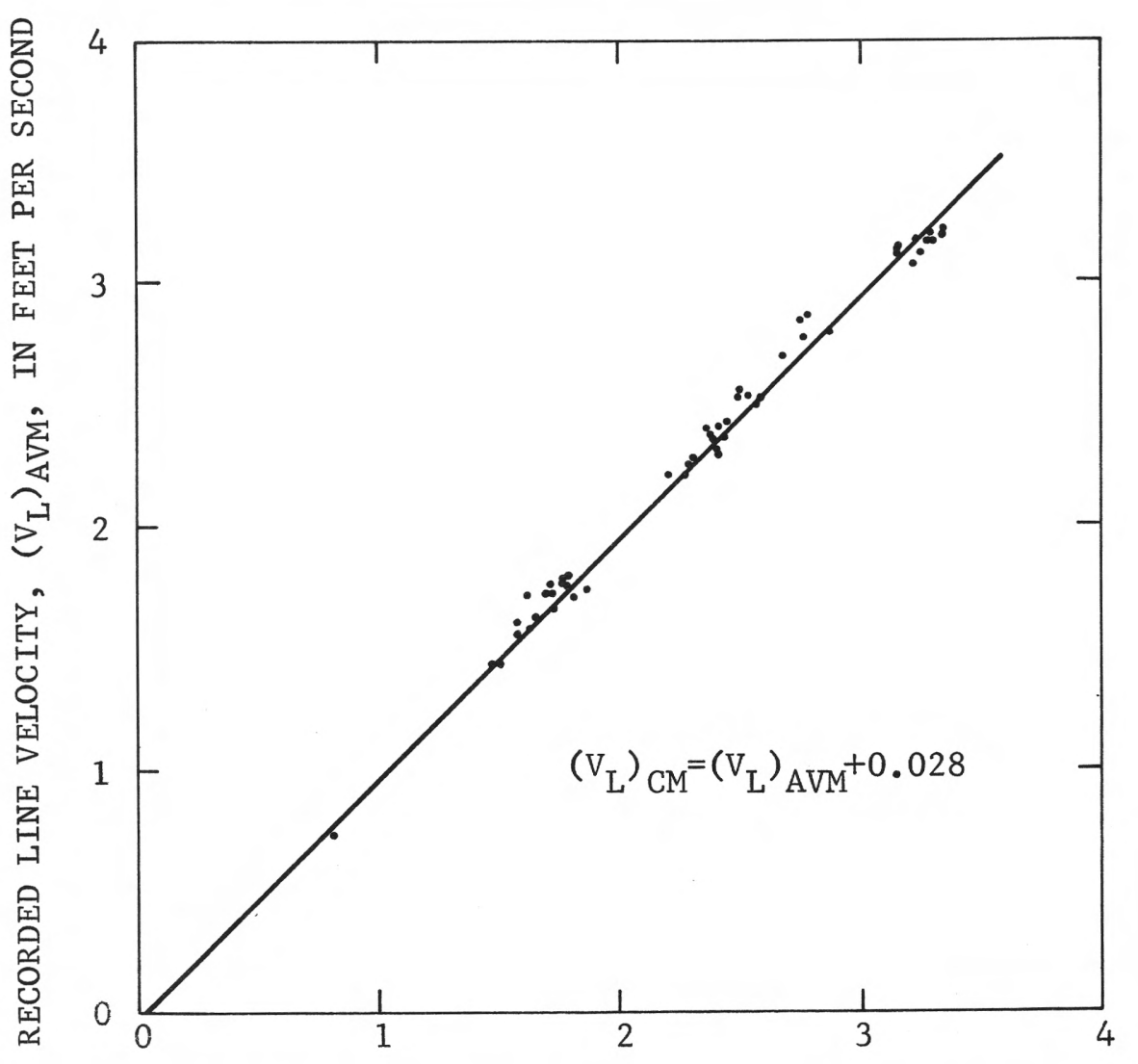

MEASURED LINE VELOCITY, $\left(\mathrm{V}_{\mathrm{L}}\right)_{\mathrm{CM}}$, IN FEET PER SECOND

Figure 8.--AVM calibration at Delta-Mendota Canal near Tracy, Calif.

Figures 8 and 9 show the relations established in the DeltaMendota Cana1, which is a large concrete-1ined trapezoidal canal, 48 feet in width at the bottom with $1 \frac{1}{2}: 1$ side slopes. Water depth in the canal is usually held between 13 and 15 feet, and discharges of as much as 4,900 cfs are carried. Figure 8 shows the stable relation between line velocities at a specified elevation recorded by an AVM and line velocities at that same elevation computed from traverses made by a conventional Price current meter. In figure 9 the variation of the ratio of the mean velocity in the cross section and the corresponding line velocity at a fixed elevation ( $5.6 \mathrm{ft}$ above the canal bottom in this instance) is shown as a function of the stage in the canal. Definition of points in figure 9 is from a series of 15 multiple-point currentmeter measurements made during the period January 1965 to September 1965. Velocity traverses at the 5.6-foot elevation were made coincident with these measurements. The regression equation of the curve shown on figure 9 is

$$
\frac{\bar{V}}{\left(V_{L}\right)_{5.6}}=0.886+0.00763 \mathrm{H}
$$

where $\mathrm{H}$ is the stage referenced to the canal bottom. 


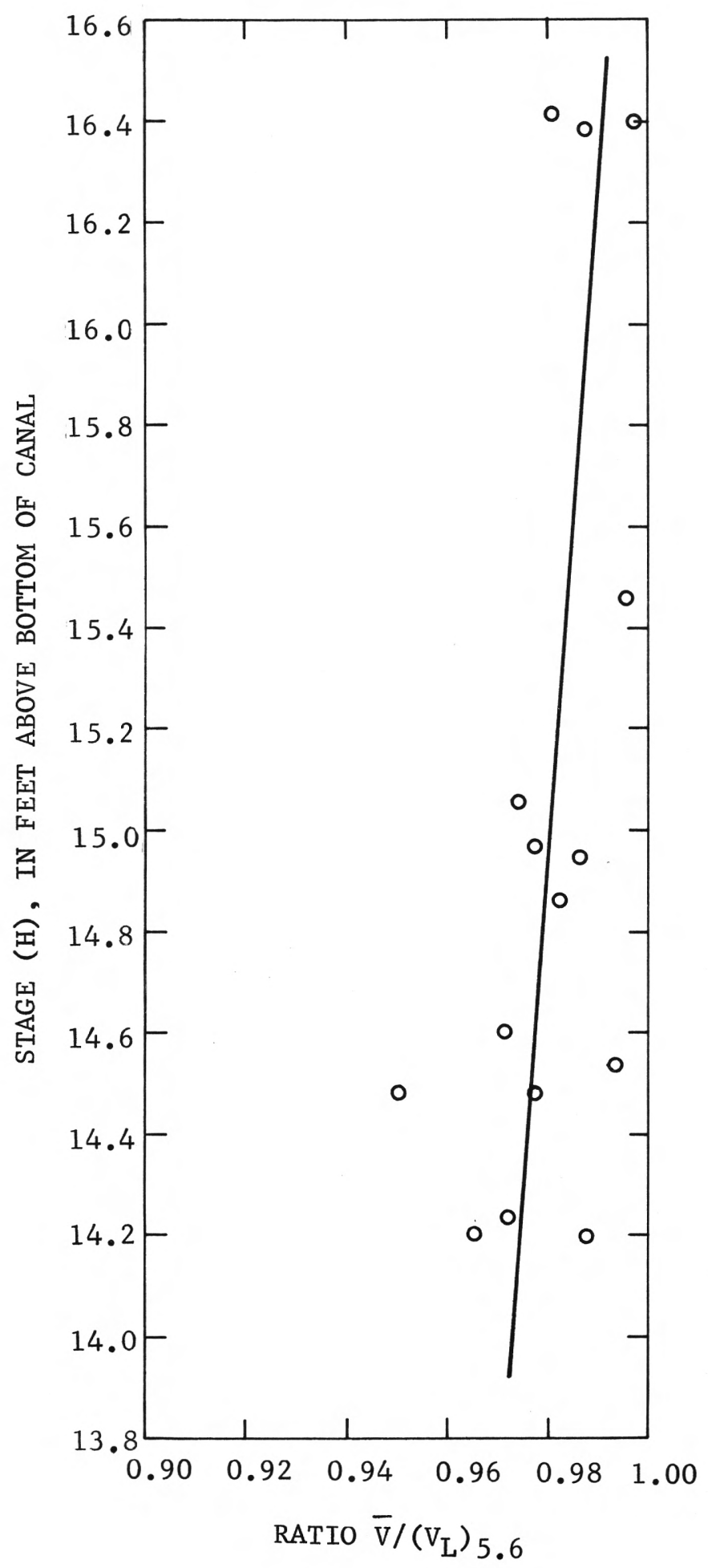

Figure 9.--Variation of ratio $\bar{V} /\left(V_{L}\right)_{5.6}$ with stage in DeltaMendota Cana1 near Tracy, Calif. 
The standard error of estimate is 1.2 percent, which is within the probable accuracy of the current-meter data.

Data from the Snake River near Clarkston, Wash., site, a typical free-flowing river about 600 feet wide at low water, are shown in figure 10. Points on this curve are line velocities recorded by an AVM plotted against the concurrent mean velocities in the cross section computed from the stage-discharge-area relations of the site. The curve shown in figure 10 was, however, computed from current-meter measurement data. It was included to illustrate the possibility of predicting the calibration characteristics of an AVM system from conventional currentmeter measurements.

Figures 8, 9, and 10 demonstrate the observed stability of the relation between a line velocity and the mean velocity in cross sections subject to open-channel flow. Similar computations have been made from current-meter measurements in the 3,000-foot-wide tide-affected channe1 of the lower Sacramento River in California where reversals of flow are encountered. These computations, reported in detail by Smith (1969), verify the stability of relations observed in the work cited above, and provide additional support to the concept of use of a line velocity as an acoustic index of the mean velocity in river channels where either open-flow regimes predominate or where extreme conditions. of variable backwater prevail.

\section{THE ACOUSTIC VELOCITY METER}

Several AVM systems have been developed using variations of the same basic theory. Common to each is the measurement of water velocity by determination of the traveltimes of sound pulses moving in both directions along a diagonal path between transducers (sound generators or receivers) mounted near each bank. The water velocity indicated by the system is the average velocity component parallel to the acoustic path, the line between the two transducers.

In the systems that have reached prototype or field-1evel configuration, three general approaches have been employed. These are the sing-around circuit, the total traveltime circuit, and the differentialtime circuit. Because the basic equations applicable to the total traveltime circuit are the simplest in concept, they are considered first in this paper. 


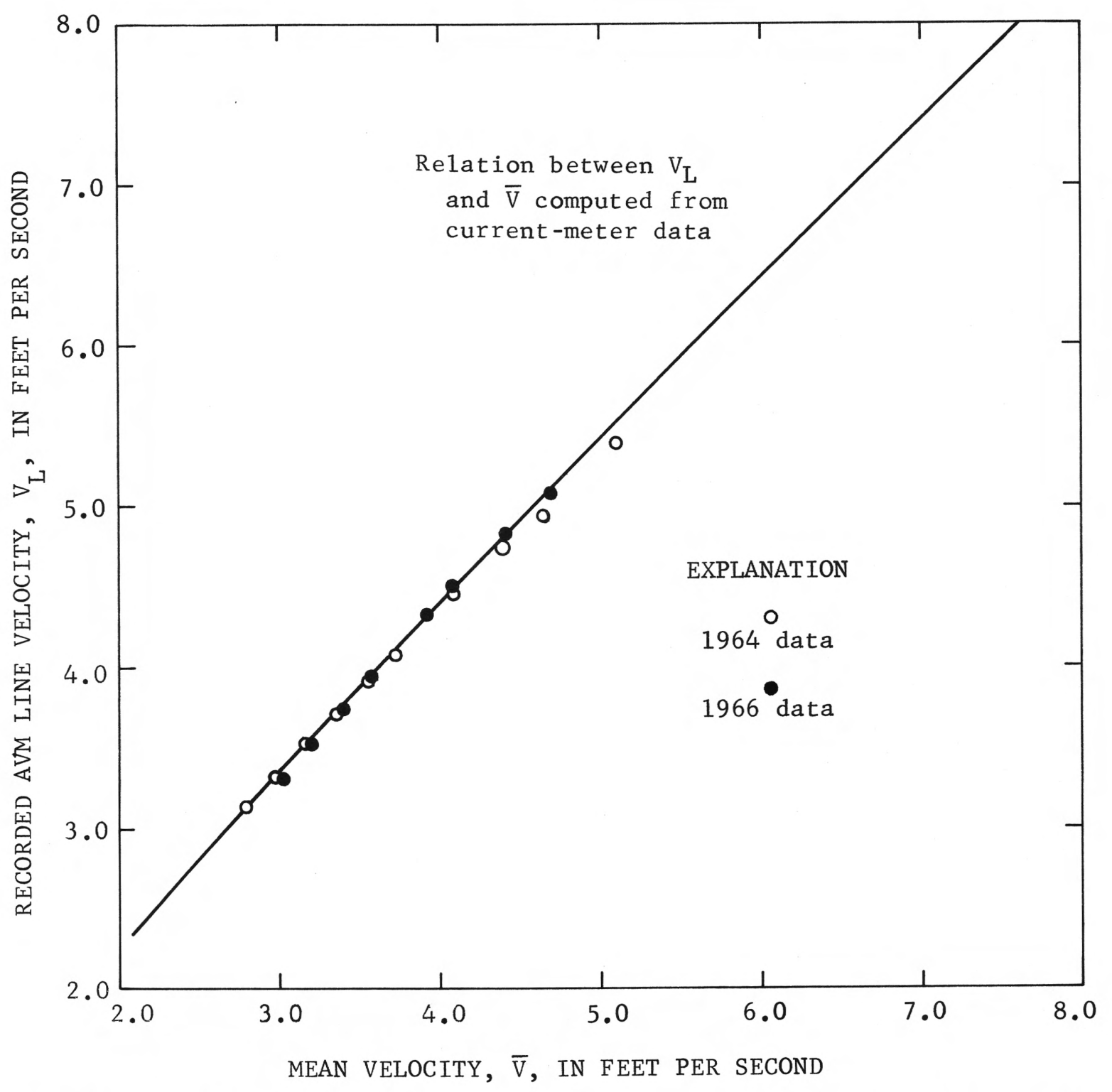

Figure 10.--Comparison between $V_{L}$, recorded by the AVM, and $\bar{V}$, computed from gaging-station records, Snake River near Clarkston, Wash. 


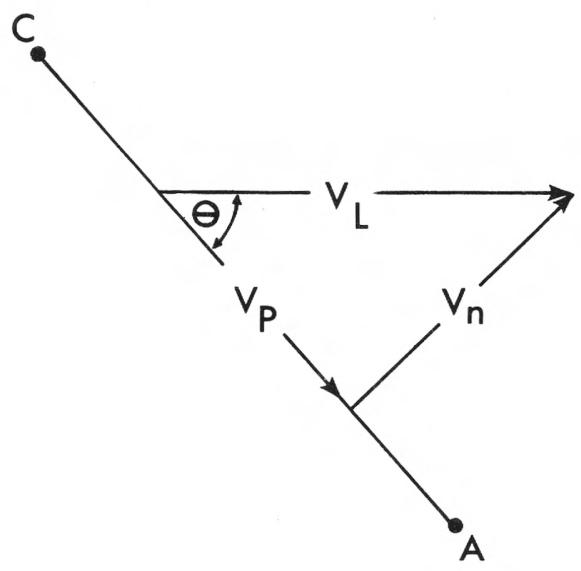

Figure 11.--Sketch to illustrate operating principles of the AVM.

\section{Total Traveltime Circuit}

Measurement of the water velocity is possible because the velocity of a sound pulse in moving water is the algebraic sum of the acoustic propagation rate (c) and the component of water velocity parallel to the acoustic path. Referring to figure 11, the mathematical relations of the system can be derived as follows.

The traveltime of an acoustic pulse originating from a transducer at $A$ and traveling in opposition to the flow of water along the path A-C can be expressed as

$$
\mathrm{T}_{\mathrm{AC}}=\frac{\mathrm{B}}{\mathrm{c}-\mathrm{V}_{\mathrm{P}}}
$$

and

$$
c-V_{P}=\frac{B}{T_{A C}}
$$

where $c$ is the propagation rate of sound in still water, in feet per second,

$B$ is the length of the acoustic path from $A$ to $C$, in feet,

$\mathrm{T}_{\mathrm{AC}}$ is traveltime from $\mathrm{A}$ to $\mathrm{C}$, in seconds, and

$\mathrm{V}_{\mathrm{P}}$ is average component of water velocity parallel to the acoustic path, in feet per second. 
Similarly, the traveltime for a pulse traveling with the current from $\mathrm{C}$ to $\mathrm{A}$ is

and

$$
\mathrm{T}_{\mathrm{CA}}=\frac{\mathrm{B}}{\mathrm{c}+\mathrm{V}_{\mathrm{P}}}
$$

$$
c+V_{P}=\frac{B}{T_{C A}}
$$

where $\mathrm{T}_{\mathrm{CA}}$ is traveltime from $\mathrm{C}$ to $\mathrm{A}$, in seconds.

Combining equations 2 and 4 and solving for $v_{P}$

$$
\mathrm{V}_{\mathrm{P}}=\frac{\mathrm{B}}{2}\left(\frac{1}{\mathrm{~T}_{\mathrm{CA}}}-\frac{1}{\mathrm{~T}_{\mathrm{AC}}}\right)
$$

and as

$$
\begin{gathered}
\mathrm{V}_{\mathrm{P}}=\mathrm{V}_{\mathrm{L}} \operatorname{Cos} \theta \\
\mathrm{V}_{\mathrm{L}}=\frac{\mathrm{B}}{2 \operatorname{Cos} \theta}\left(\frac{1}{\mathrm{~T}_{\mathrm{CA}}}-\frac{1}{\mathrm{~T}_{\mathrm{AC}}}\right)
\end{gathered}
$$

where $V_{L}$ is the line velocity, the average water velocity at the elevation of the acoustic path, in feet per second.

$\Theta$ is the angle of departure between the streamline of flow and the acoustic path.

In this type of system; correction for changes in the acoustic propagation rate of sound are automatically compensated for by the treatment of data given in equation 7 .

In a system built on the total traveltime circuit, traveltimes are measured sequentially for pulses originating at A traveling against the current, and then for pulses originating at $\mathrm{C}$ traveling with the current. Accuracy of a system of this type depends on the precision with which the individual traveltimes can be measured. Errors in indicated velocities are a linear function of timing errors in either direction. A detailed discussion of a system of this type is given in the report by Smith and Wires (1967).

\section{$\underline{\text { Sing-Around Circuit }}$}

The sing-around circuit concept, sometimes referred to as the pulse-repetition frequency system (Barron, 1963), has been proposed by several developers. In such a system, cumulative measurements of traveltimes are made by using the received pulse at the far end of an acoustic path to immediately trigger a second transmit pulse at the originating transducer. Arrival of this second pulse triggers the next transmission, and the system is allowed to continue operation in this repetitive pattern. Transit time of the acoustic wave is resolved either by measurement of the total time for completion of a fixed number of cycles or by reduction of the cycling rate to a continuous pulse-repetition frequency. Where a single pair of transducers is 
employed, such systems usually measure transit times for a given period in one direction along the acoustic path and then in the other direction. One system proposed simultaneous operation in both directions by utilizing different frequencies of transmission with a single pair of transducers. Another system, developed to prototype level (Barron, 1963), used two pairs of transducers tuned to different frequencies in the two directions.

The quotients $1 / \mathrm{T}_{\mathrm{CA}}$ and $1 / \mathrm{T}_{\mathrm{AC}}$ in equation 7 are the pulserepetition frequencies for acoustic transmissions in each direction that would be measured in a sing-around circuit system. It follows that the respective pulse repetition frequencies can be substituted for these quotients, and with this minor change, equation 7 is applicable to the sing-around circuit system.

Successful application of the sing-around circuit to date (1970), has been 1 imited to measurement of flows in conduits and smaller channels, but at least two systems for use in large channels are now in the design stage. Difficulties encountered have usually been associated with problems of acoustic-signal recognition and maintenance of stable operations.

\section{Differentia1-Time Circuit}

The differential-time circuit differs from the two circuits previously discussed in that the difference in the time of arrival of acoustic pulses, triggered simultaneously at each end of the path, is directly measured. When two transducers transmit signals simultaneously toward each other, the flow of water in the path will increase the speed of one signal and decrease the other. The signal transmitted in the downstream direction arrives first and is used to start a timeclock; the signal transmitted in the opposite direction arrives later in time and is used to stop the clock. The time increment recorded is thus the differential between the total traveltimes involved, a differential that is linearly proportional to the water velocity. In this system, the measure of the average total traveltime in each direction must also be recorded to compensate for changes in the speed of sound in water resulting from changes in temperature or in dissolved solids. 
Referring to figure 11, equations for the differential-time circuit can be derived as follows.

$$
\begin{aligned}
\mathrm{T}_{\mathrm{AC}} & =\frac{\mathrm{B}}{\mathrm{c}-\mathrm{V}_{\mathrm{P}}} \\
\mathrm{T}_{\mathrm{CA}} & =\frac{\mathrm{B}}{\mathrm{c}+\mathrm{V}_{\mathrm{P}}}
\end{aligned}
$$

$\Delta \mathrm{T}$ is the difference between $\mathrm{T}_{\mathrm{AC}}$ and $\mathrm{T}_{\mathrm{CA}}$

$$
\Delta T=\frac{B}{c-V_{P}}-\frac{B}{c+V_{P}}=\frac{2 B V_{P}}{c^{2}-V_{P}{ }^{2}}
$$

and since $\mathrm{V}_{\mathrm{P}}{ }^{2} \ll \mathrm{c}^{2}$

$$
\Delta \mathrm{T} \cong \frac{2 \mathrm{BV}}{\mathrm{c}^{2}} \mathrm{P}
$$

or

$$
\mathrm{V}_{\mathrm{P}} \cong \frac{\Delta \mathrm{Tc} \mathrm{c}^{2}}{2 \mathrm{~B}}
$$

Both $\Delta T$ and $\mathrm{c}$ in equation 10 can be defined by measurement of traveltimes of acoustic signals transmitted in each direction between transducers.

Comparison of equations 7 and 10 suggests that the latter is the less satisfactory manipulation of the basic equations 1 and 3 because it retains the sound propagation velocity c. However, experience with various AVM systems has shown that measurements of $\Delta \mathrm{T}$, defined by differences in the arrival times of signals transmitted simultaneously in both directions, tend to be more accurate than measurements of the individual traveltimes. It can also be shown that errors in computed water velocity resulting from errors in observation of individual traveltimes are smaller when used with equation 10 than they are when used with equation 7. Definition of $c$ is made by combination of equations 2 and 4 and solving for $c$ instead of $V_{P}$ as was done for equation 5 .

The AVM system developed by the Westinghouse Electric Corp. and marketed under the trade name "Leading-Edge Acoustic Flowmeter"1/ utilizes the differential-time circuit. Several of these systems, including the one on the Columbia River; are now in service.

1/ References to the Westinghouse Leading-Edge Acoustic Flowmeter, a registered trade name of Westinghouse Electric Corp., sha11 not be construed as an official endorsement of this particular product by the U.S. Geological Survey. 
Acoustic signals generated by the transducers produce a received wave train such as shown in figure 12. The burst of energy arriving first in time represents the direct transmission along the line between the two transducers. Following this may be one or more signals which are reflections from the water surface or river bottom. Arrival of the signal is coincident with the first negative drop of the wave train. This is shown more clearly in figure 13 which is a time amplification of the first part of the received signal as shaped by the amplifying circuits of the system. The peak of the first negative cycle, however, is generally of a lower amplitude than the first positive peak. After the initial cycle, the waveform may become complex because of harmonics generated by the signal-conditioning system or by the arrival of outof-phase wave components reflected perhaps from suspended solids or from temperature gradients or turbulence along the acoustic path. Therefore, accurate reproduction of the transmit pulse may be achieved only during the first few cycles of the received wave train. Recognition of the time of signal arrival is best made during the first cycle.

The ideal signal-detection system would be one that recognizes the precise beginning of the received pulse train (point A, fig。13). However, this is not practical because system noise may effectively mask the low-amplitude part of the signal, as shown in figure 14. This figure is an oscilloscope trace of the received signal carried back to the central processor over 4,500 feet of line from the far-bank transducer at The Dalles installation. From figure 14, it is evident that signals must vary significantly from the zero position before recognition can be made. This implies that there will be a definite lag between the actual time of signal arrival and the time recorded by an AVM system. If this time delay is equal for transmission in both directions, no significant errors result in system readout, but readout errors, proportional to the difference in time delays, result if systematic differences are present.

Four differing signal-recognition methods have been employed by various developers of AVM systems. These are: (1) the leading-edgedetection method, employed successfully by Westinghouse Electric Corp. and the Geological Survey; (2) a method that utilizes the differential of the voltage-time pulse train; (3) a method that recognizes the first zero crossover after the first peak above a given threshold 1evel; and (4) a method comparing phase relations of the received to transmitted signa1. Only the leading-edge-detection method is discussed in this paper.

The leading-edge signal-detection method is the simplest in concept and the one that has proven to be most reliable to date. Signals from the transducers are filtered to reduce system noise, amplified to a suitable level, and then routed to a so-called Schmitt trigger, which is responsive to voltage leve1. Output of the Schmitt trigger is a 


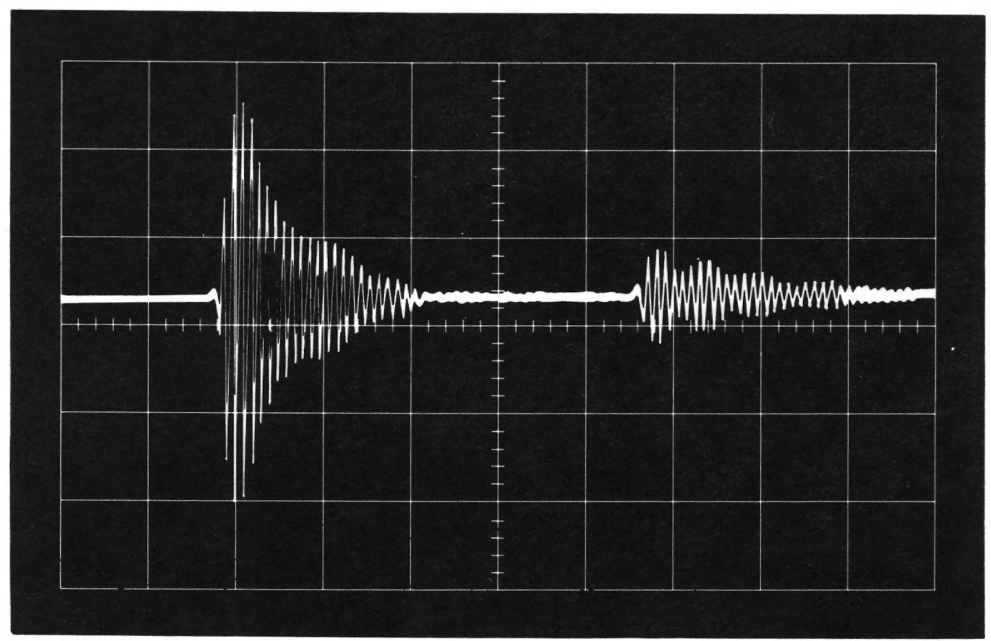

Sweep rate: 100 microseconds per centimeter Vertical scale: 1 volt per centimeter

Figure 12.--Oscilloscope trace of acoustic wave received at the near side of the AVM system at The Dalles, Oreg.

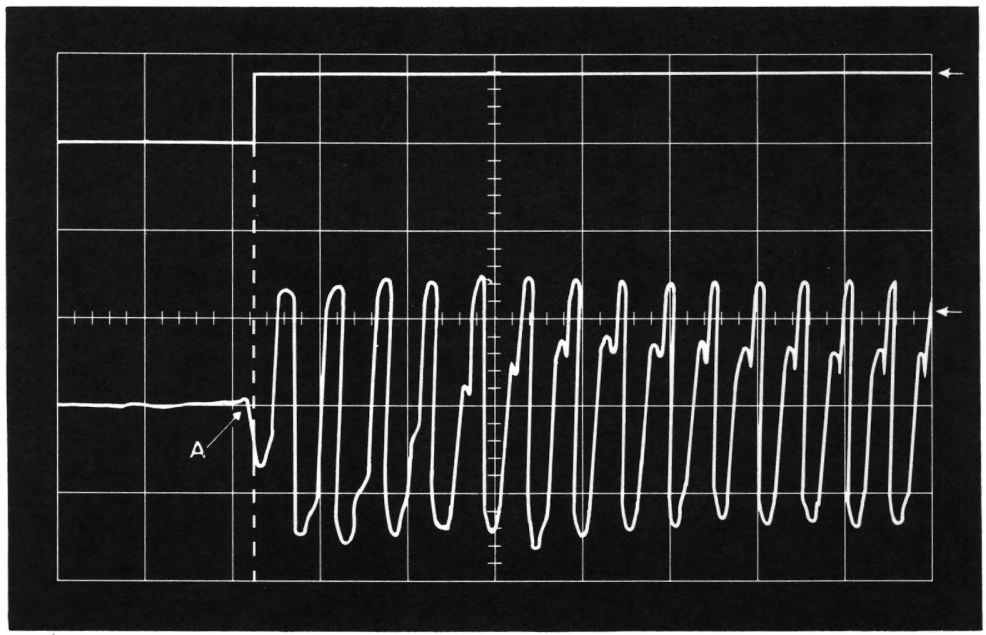

Trigger

pulse

Sweep rate: 20 microseconds per centimeter Vertical scale: 0.5 volts per centimeter

Figure 13.--Expanded oscilloscope trace of the acoustic wave as shaped by amplification and the trigger pulse for the AVM system at The Dalles, Oreg。 


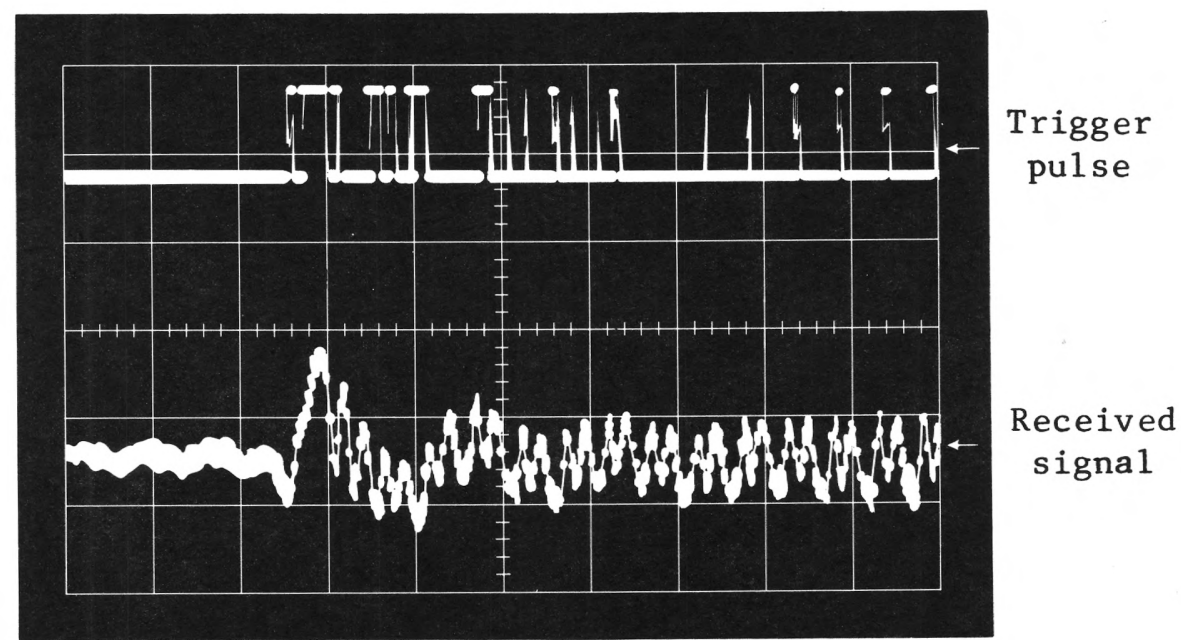

Sweep rate: 20 microseconds per centimeter Vertical scale: 1 volt per centimeter

Figure 14.--Oscilloscope trace of acoustic wave received at the far side and transmitted over 4,500 feet of 1 ine to the central processor of the AVM system at The Dalles, Oreg.

fast-rising voltage change coincident with the time that the input voltage reaches a set threshold. This signal-detection scheme permits recognition during either the first negative-going or the first positivegoing excursion of the pulse train. The threshold level must be set at a value greater than the system noise level, a requirement that sometimes results in failure to recognize the initial pulse of the wave train. Due to variations in the attenuation of the signal as it travels over the acoustic path between transducers, amplitude of the received wave train may vary. Consequently, the lag between the actual time of arrival and the time of detection will vary depending on whether or not the threshold level is reached early or late in the cycle. The first peak may be even less than the threshold level, in which case the trigger will respond to any of the following cycles that do reach the threshold level. If attenuation of signal is too large, this set threshold may not be reached at all during a given transmission, and the time of signal arrival will not be recorded. Provisions must be made within the AVM system for handling periods of signal failure, which may occur at random intervals. Discussion of the particular correction technique employed in the Westinghouse Leading-Edge Acoustic Flowmeter is given on page 35 . 


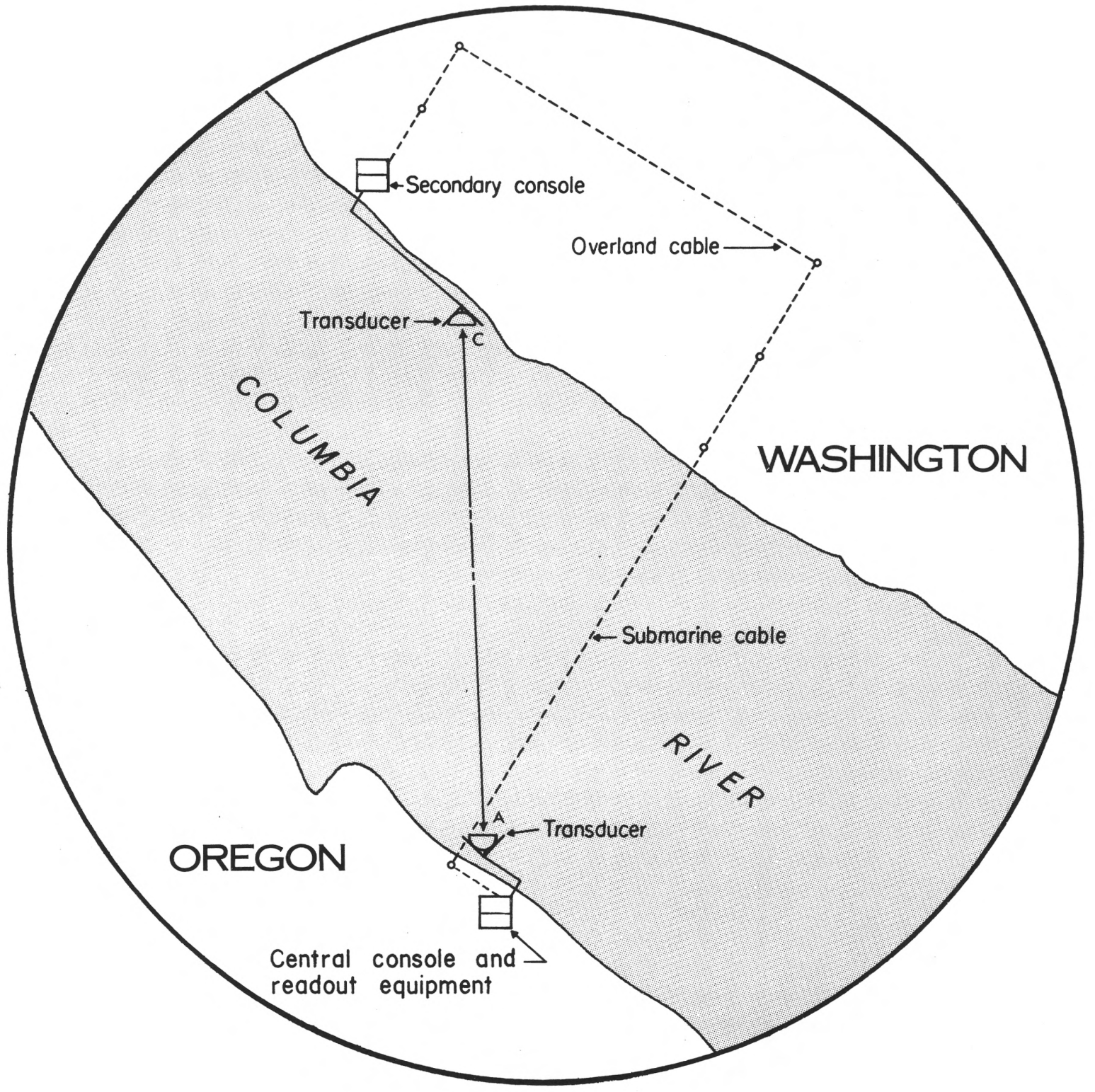

Figure 15.--Layout of AVM system.

THE ACOUSTIC STREAMFLOW-MEASURING SYSTEM AT THE DALLES

The Westinghouse Leading-Edge Acoustic Flowmeter selected for use at The Dalles is an acoustic velocity-metering system utilizing the differential-time circuit and the leading-edge signal-detection method. Physical location of system components is shown in figures 15 and 16. Figure 15 is a detail map showing the layout of the AVM system circled in figure 2, and figure 16 is an artist's sketch of the structures and the site. The block diagram shown in figure 17 further delineates the 


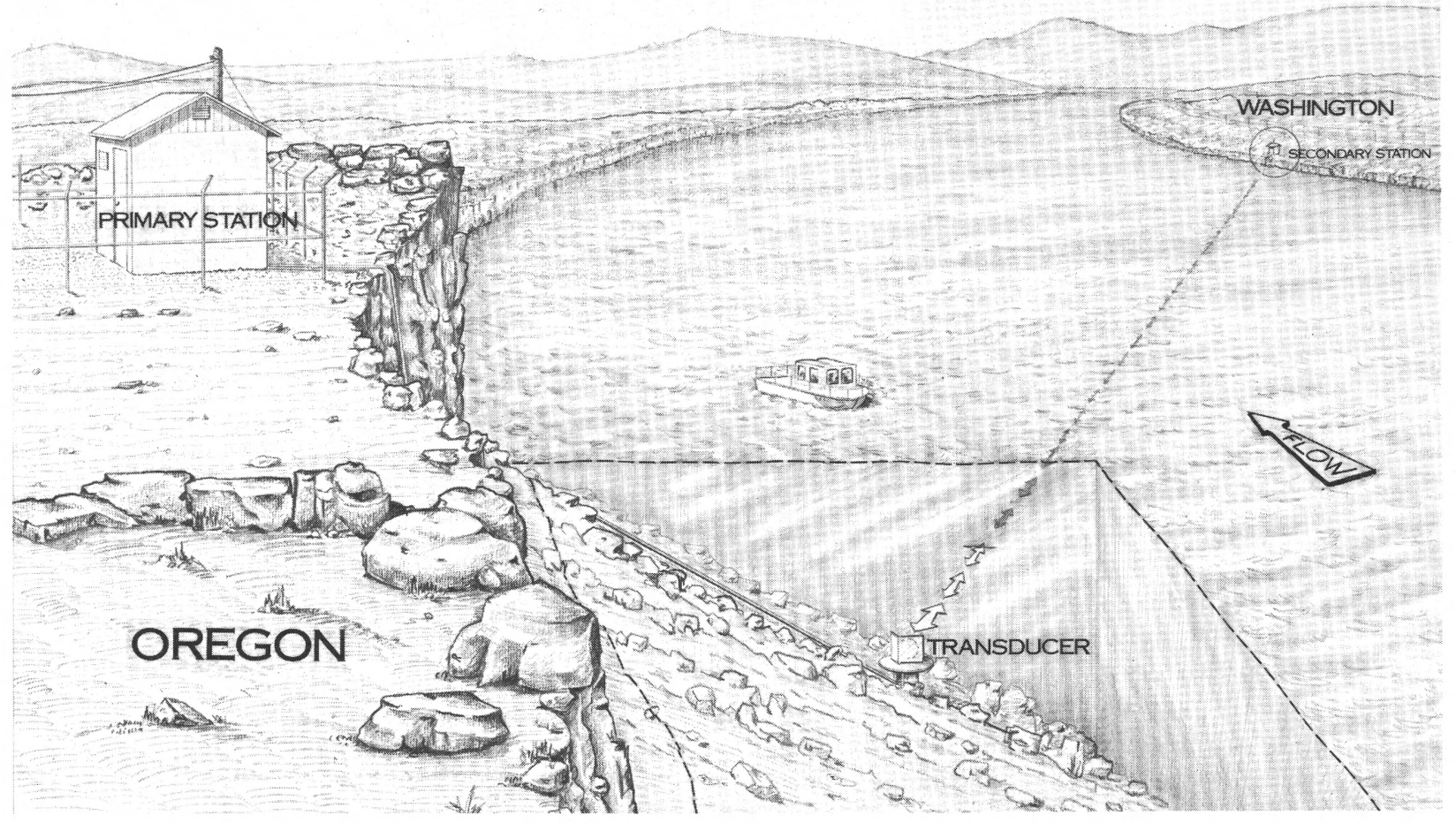

Figure 16.--Artist's sketch of structures at The Dailes, Oreg.

major components of the system, which consists of two submerged transducers, a central console in the primary shelter near the south end of the diagonal acoustic path, and a secondary console in a shelter near the north end of the acoustic path. Communication lines interconnect these two consoles, and separate lines run from each console to the respective transducers.

Detail of the transducers is shown in figure 18. These units act alternately as transmitters and receivers. One transducer is located at each end of the 1,320-foot diagonal path (points A and C, fig. 15)。 Vertical placement of the transducers, at elevation 38 feet, is shown in figure 19, which is the vertical profile along path A-C. Steel H-beam piles were driven to refusal and cut off at the proper level to provide a secure mount for each transducer. The stage record for the system is obtained by means of a shaft encoder (stage digitizer) coupled to a standard U.S. Geological Survey bubble gage. 


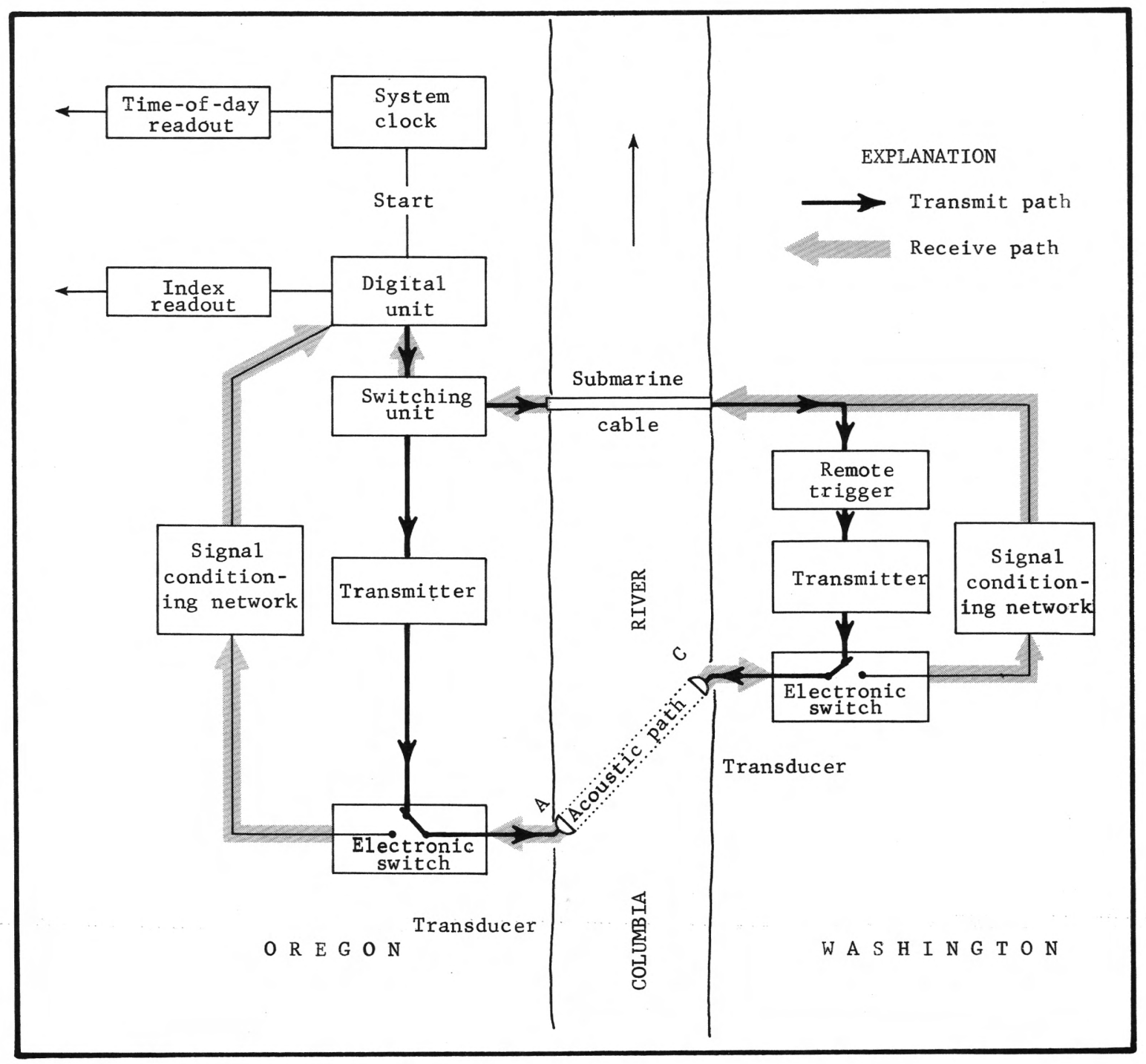

Figure 17.--Block diagram of AVM system. 


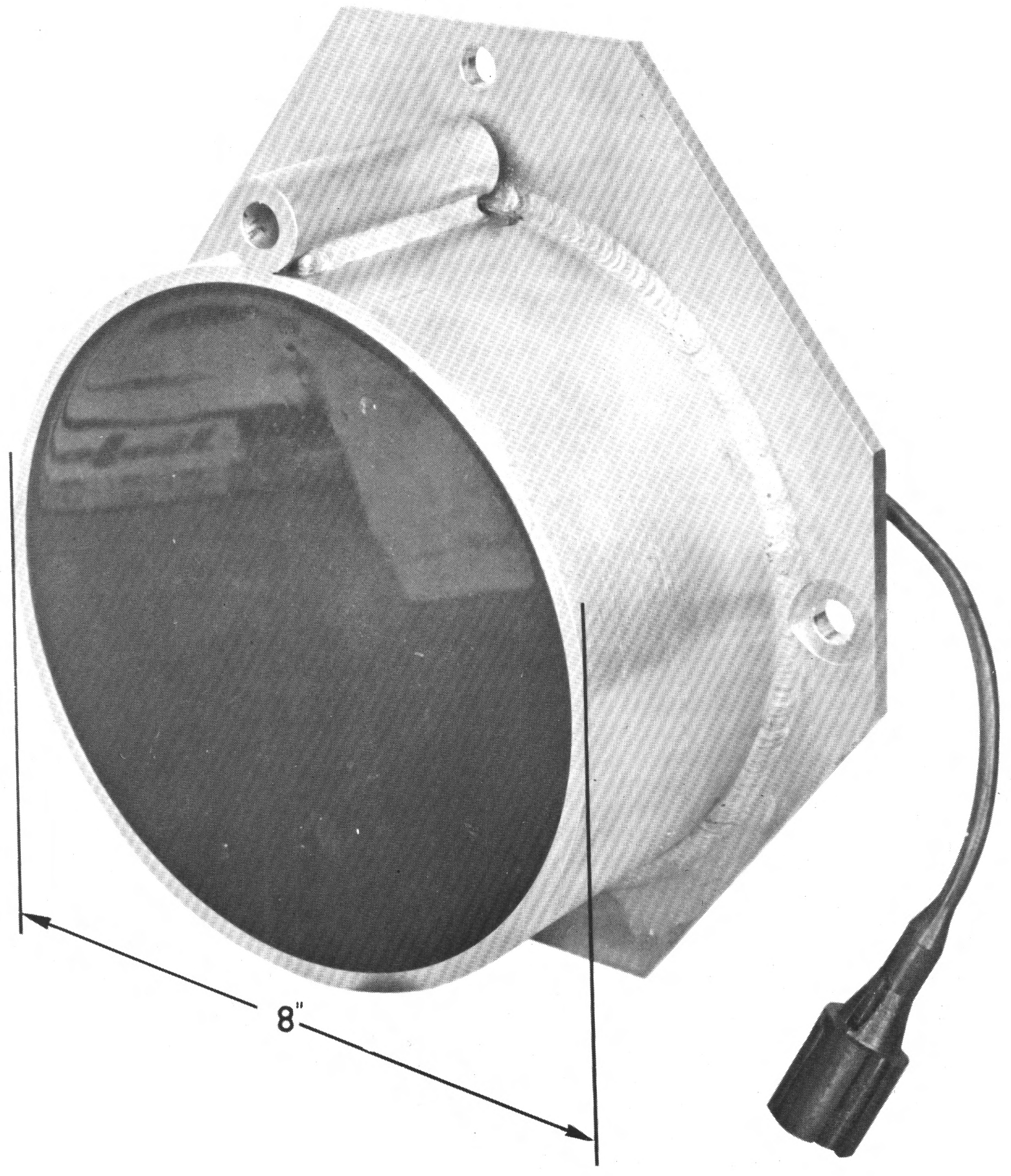

Figure 18.--Transducer. 


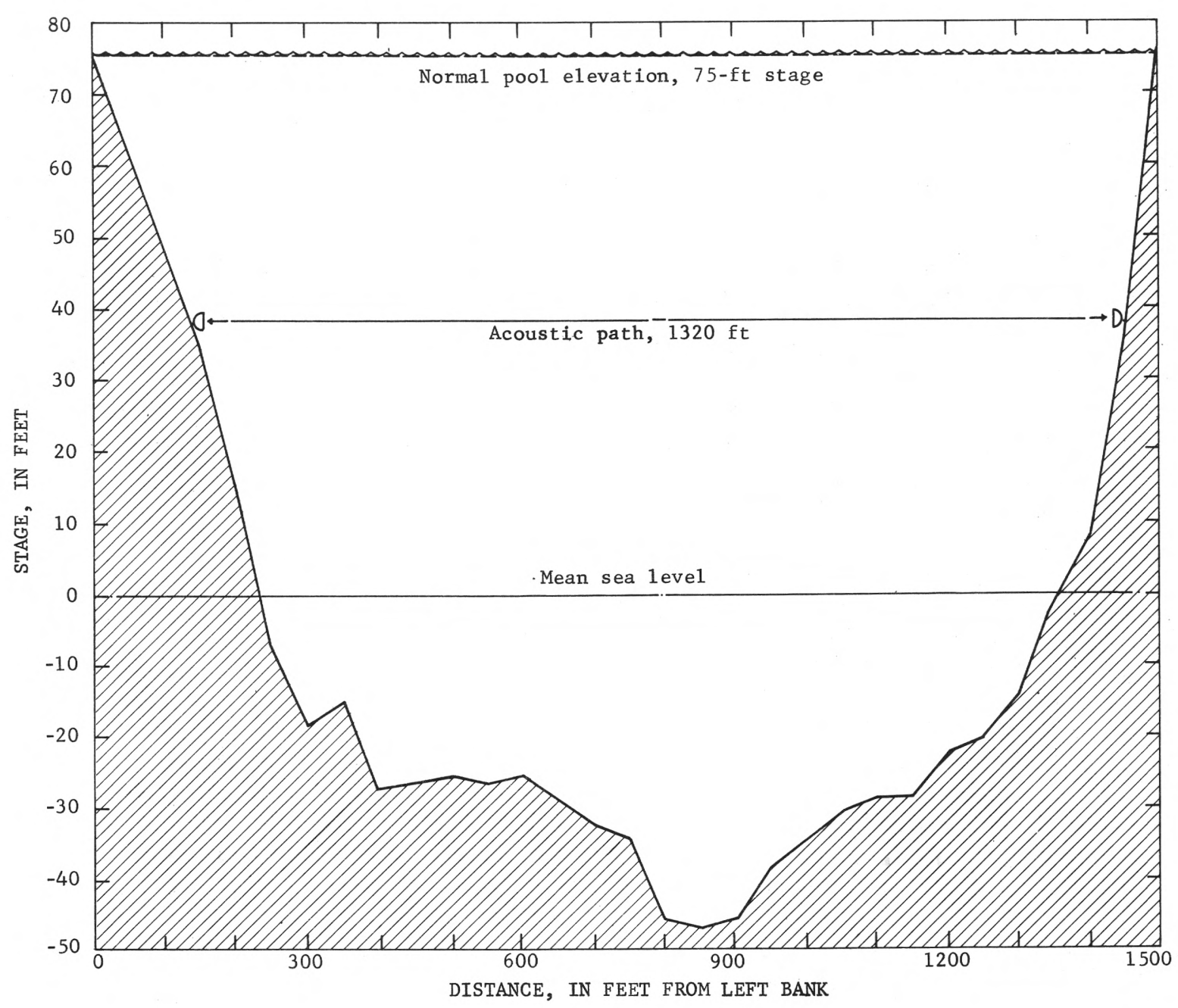

Figure 19.--River cross section along the acoustic path at The Dalles, Oreg., site.

The central console, shown in figure 20, contains the operating controls, the velocity-index display, the signal-generating and receiving circuits (the acoustic unit), the digital processor (the digital unit) which controls the transmissions and performs the computation of the velocity index, and the system clock which provides the basic timing pulses for the system and also furnishes the time-of-day readout. The secondary console ( $\mathrm{fig}, 21$ ) is at the far end of the system and is a slave unit that generates and receives the signals for the remote transducer. Communication between the two consoles is via a submarine cable crossing the river just downstream from the shelter that houses the central console and other equipment. 


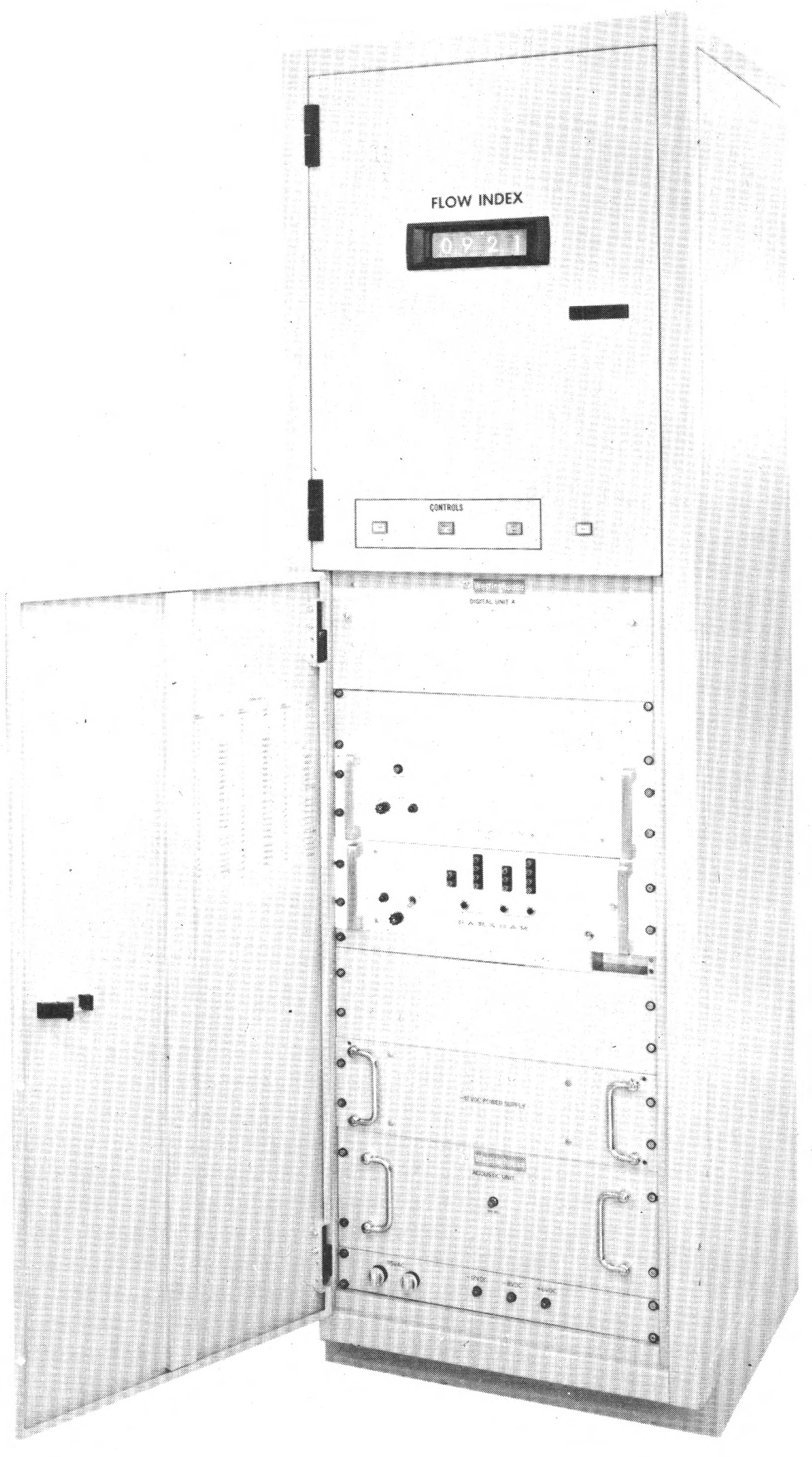

Figure 20.--Central console. 


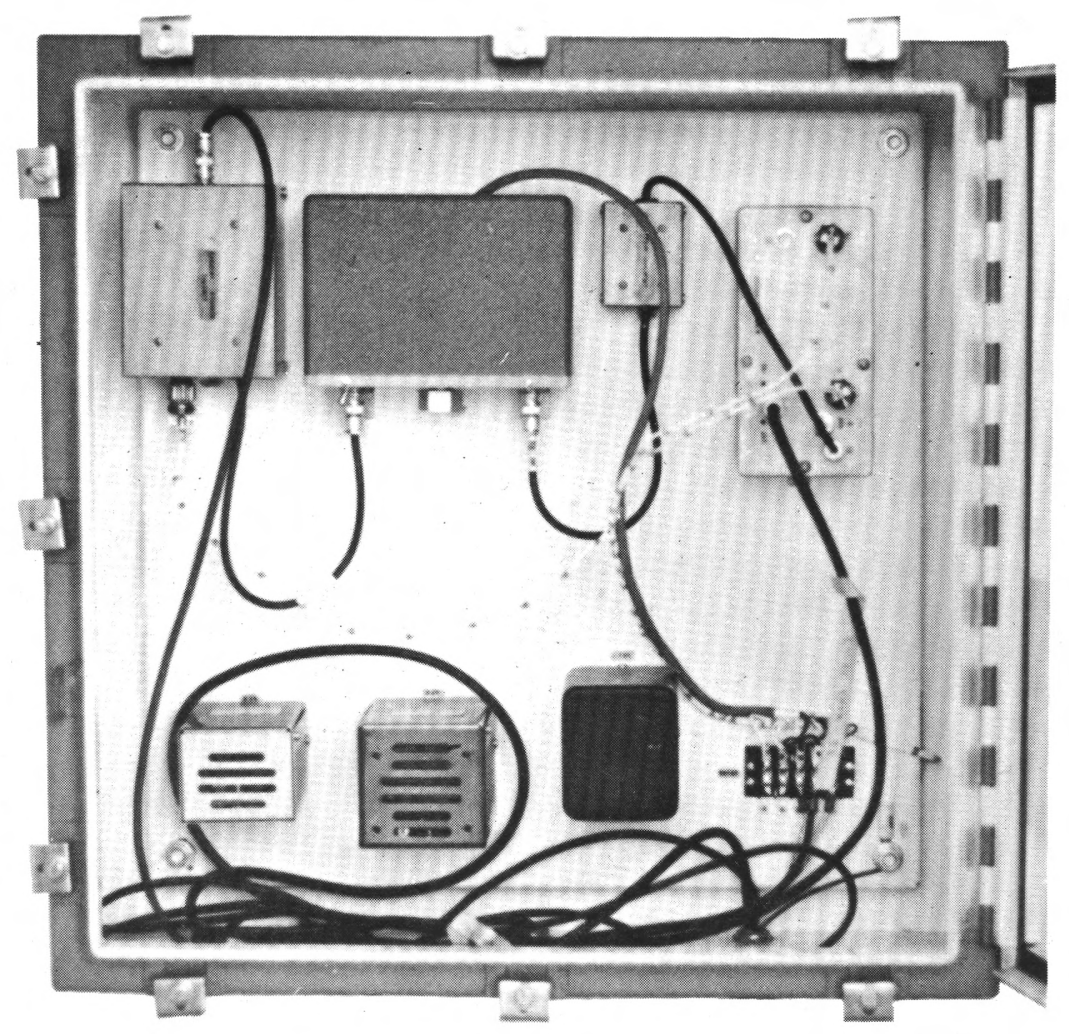

Figure 21.--Secondary console.

\section{Layout of Equipment}

The physical arrangement of equipment in the main shelter is shown in figure 22. Peripheral equipment, the bubble gage and stage digitizer, the teletype equipment used to record the data, and the buffer unit to interface between the central console and teletype equipment, occupy a major part of the space. Records are collected in dual format (punched paper tape and hard copy) at the site, and a duplicate hard copy is produced on a second teletype unit in the control room of The Dalles powerhouse about 3 miles away.

\section{Data Output}

Data output from the system is illustrated in figure 23, which is a copy of the printout from the teletype printer. Data include the station number and year as a single 12-digit number, the time of day, the gage height, and the velocity index. An asterisk is printed ahead of the recorded velocity index to flag periods of doubtful record-periods when data generated in the digital unit fail to meet specified error checks built into the computation process. 


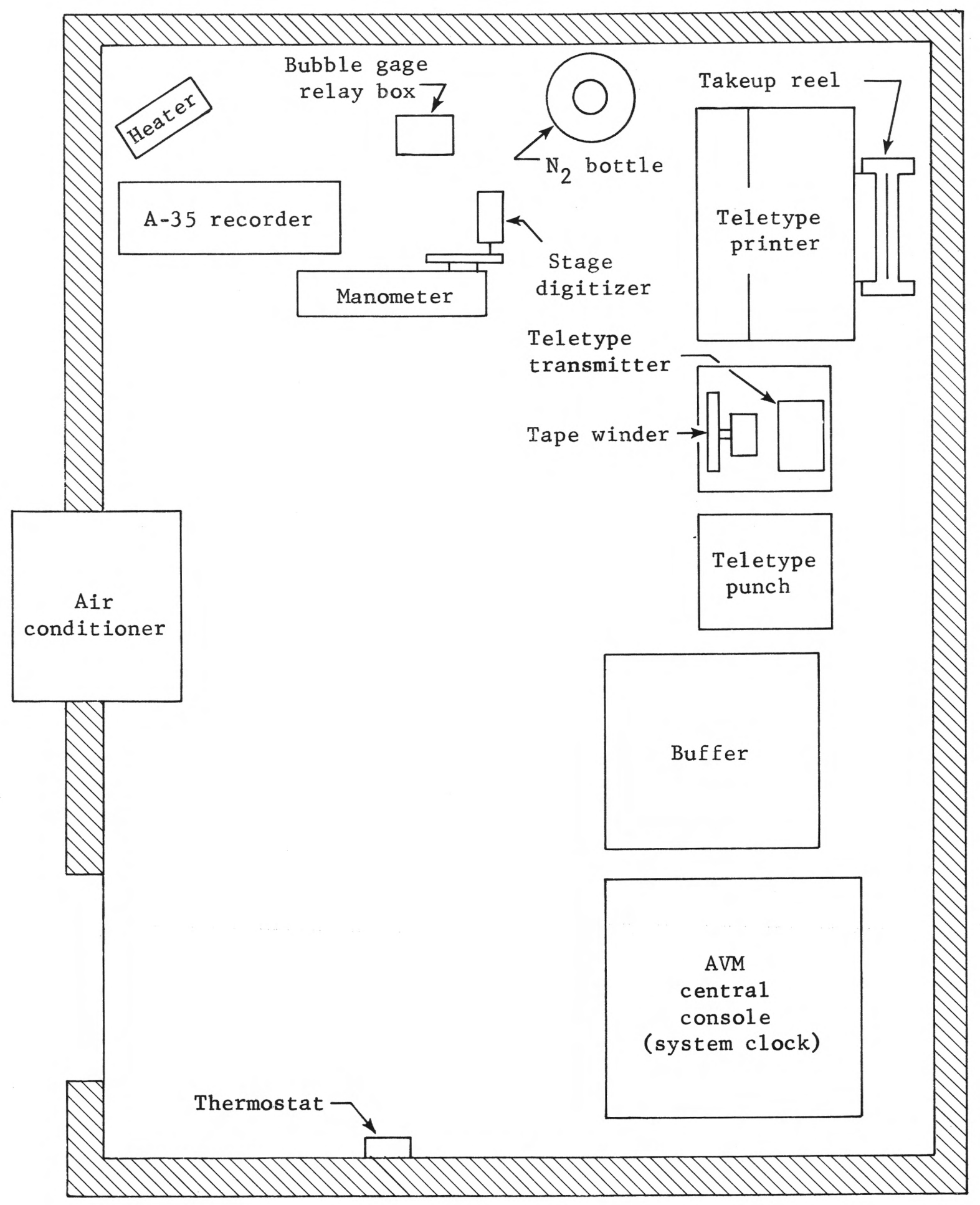

Figure 22.--Sketch of physical arrangement of equipment in 10- by 12 -foot primary shelter at The Dalles, Oreg. 
COLUMBIA RIVER AT THE DALLES, OREGON

FLOWMETER

DEC. 2, 1969

$14-1057.00$

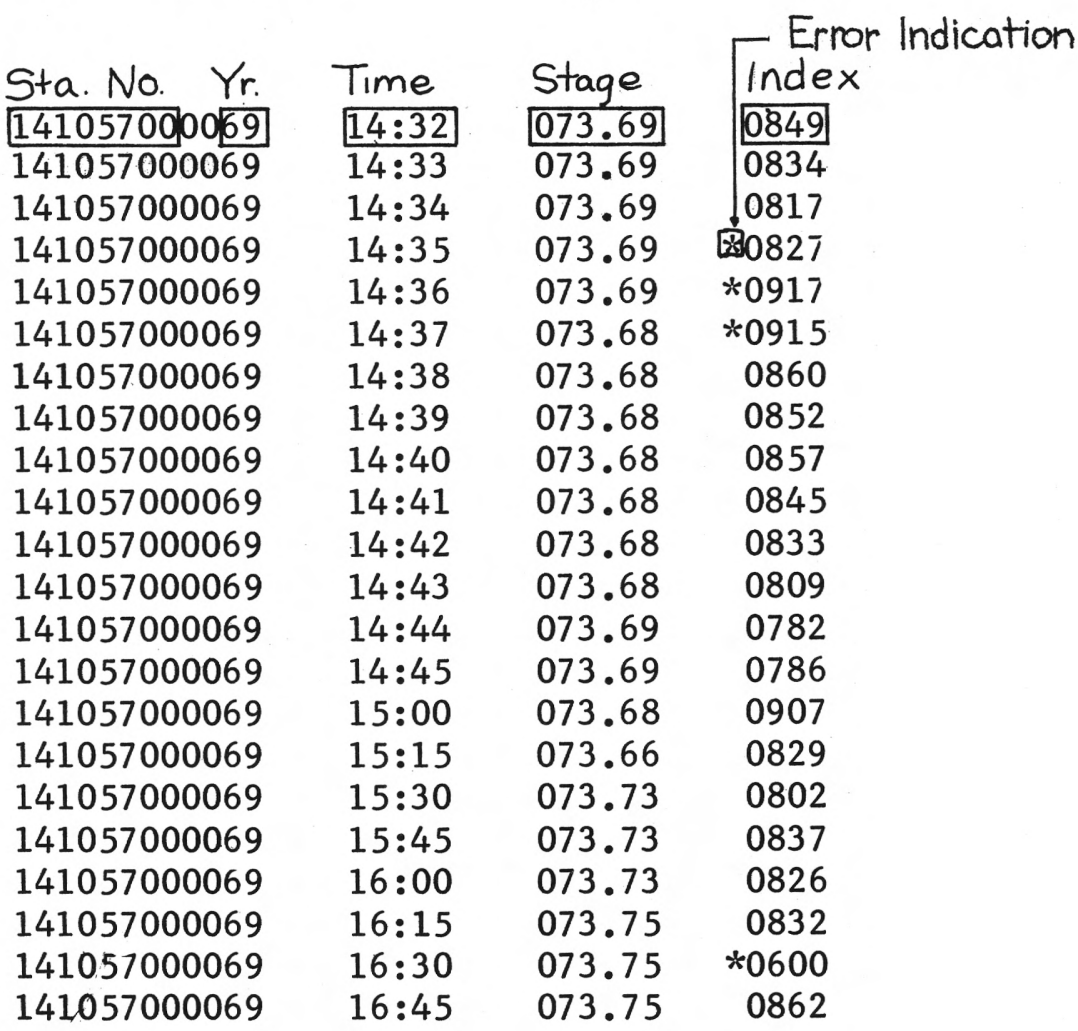

Figure 23.--Copy of printout from AVM system. 


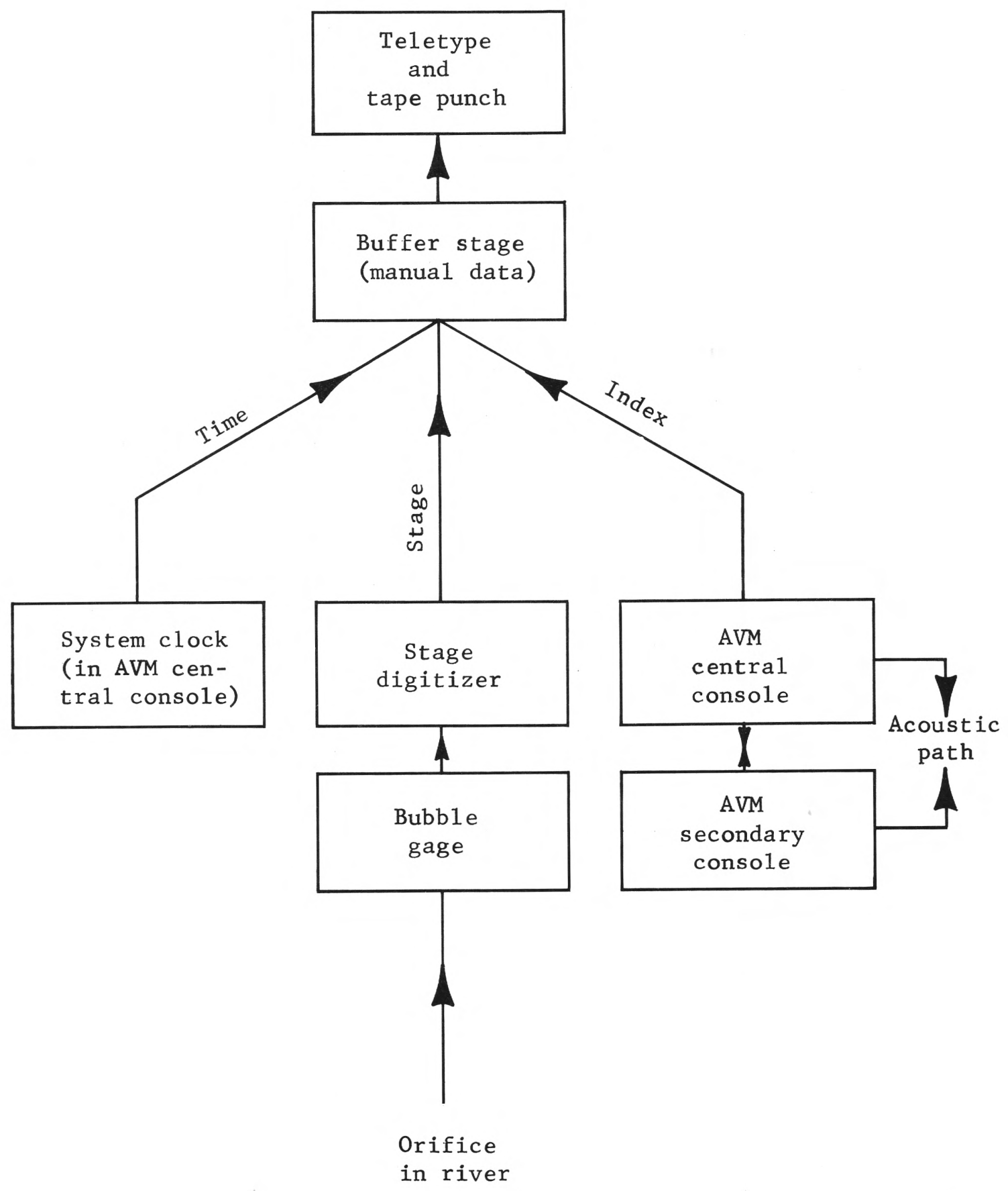

Figure 24.--Output system.

Figure 24 is a block diagram showing origin and flow lines for each data item. The station number and year are fixed data stored in the buffer stage. The time of day originates from the system clock, the gage height originates from the stage digitizer, and the velocity index is generated in the digital unit of the central console. Each data item is held in parallel BCD (binary coded decimal) format for callout at any time. This permits manual interrogation of the system at any time or 
automatic programed interrogation, by signal from the system clock, at selectable intervals of 1 minute or 15 minutes. At the time of interrogation, the readout system sequentially scans the parallel array of data, converts each item from BCD to the character code required for input to the teletype equipment. The data is then fed in serial form into the teletype circuitry for punched paper tape and hard-copy printout at the site and hard-copy printout at the remote teletype console at The Dalles powerhouse.

\section{Internal System Operation}

The basic theory and the fundamental equations of this system have been outlined in the previous discussion of the differential-time circuit. Equation 10 is the basic system equation

$$
\mathrm{V}_{\mathrm{P}} \cong \frac{\Delta \mathrm{Tc}^{2}}{2 \mathrm{~B}}
$$

where $\Delta \mathrm{T}$ is the difference in arrival times for signals transmitted simultaneously from the opposing transducers at the two ends of the acoustic path,

$c$ is the propagation rate of sound in still water, and

$B$ is the length of the acoustic path.

Measurements made by the system are those needed to define $\Delta \mathrm{T}$ which varies linearly with water velocity and $c$ which varies with the temperature and the dissolved solids of the river. To accomplish these measurements, the difference in traveltimes of the two acoustic signals and the total traveltime for acoustic propagation in each direction are measured against separate clocks.

Operation of the AVM system is controlled by the system clock, as shown in figure 17. This digital clock, which provides the time of day for external readout, also provides the timing signals that initiate individual acoustic transmissions and the updating and readout of the velocity-index display. Acoustic transmissions are regulated by a pulse train of 120 pulses per minute, and updating of the readout is controlled by a pulse generated once a minute. The readout represents the average velocity index generated from the preceding 120 acoustic transmissions. Switch of readout interval from once every minute to once every 15 minutes is accomplished by setting of the mode switch which reduces the pulse rate of both signals by a factor of 15 .

The arrival of the control pulse in the digital unit sends simultaneous control pulses to the acoustic units of both the central and secondary consoles. The control pulse, routed directly to the acoustic unit of the central console, triggers a $1,000-\mathrm{v}$ transmit pulse which is routed through an electronic switch of unique design to the upstream 
transducer. This same control pulse is routed also, via the submarine cable through the remote trigger and acoustic transmitter in the secondary console, energizing the transducer at the far end of the system. Acoustic signals are thus generated at each end of the system at approximately the same time. The signal projected downstream arrives first because its rate of travel is increased by the water velocity. This signal is received by the downstream transducer, routed through an electronic switch to the signal-conditioning net (amplifier, tuning net, and line driver), and thence through the submarine cable back to the primary console. Arrival of this signal is recognized by the leadingedge technique, previously discussed, and initiates the start of the time count for $\Delta \mathrm{T}$. The acoustic signal originating at the downstream transducer, traveling along the same acoustic path in opposition to the flow, arrives later in time, is received by the upstream transducer, and is carried through an identical switching and signal-conditioning system into the primary console where it is used to stop the count of $\Delta \mathrm{T}$ 。

Measurements of the total acoustic traveltimes are initiated by the same control pulse. Average acoustic-transmission time is obtained by observing alternately the total time for travel in the downstream direction and the total time for travel in the upstream direction. Data for computation of $c$ are thus accumulated at half the sampling rate used for $\Delta \mathrm{T}$. Generation of the acoustic signal at the far end of the system actually occurs slightly later in time because of transmission delays in the electronics and in the intervening 4,500 feet of line. This time delay is essentially canceled by an equal time delay incurred in the transmission of the received signal back to the central console over the same electrical path.

Computations of the velocity index, corrected for any changes in c, are made after each observation of $\Delta \mathrm{T}$. These are averaged for the 120sample data unit and brought out in the display. Each of the 120 data entries is checked for continuity with preceding data to eliminate spurious information from the averages. This is done by comparing each new velocity-index value with the preceding value held in memory. If the new value indicates a velocity change of more than 0.2 fps (feet per second), it is considered invalid and the value stored in memory is used in the average summation. If numbers from memory are used more than 32 times within the sampling interval, the velocity index for the period is considered to be unreliable and is flagged with an asterisk on the printout as shown in figure 23 .

\section{History of Installation}

Stream-gaging problems at the Columbia River at The Dalles were recognized as early as 1957, when a research program on the development of an AVM was first initiated as a cooperative project between the U.S. Army Corps of Engineers, the California Department of Water Resources, and the U.S. Geological Survey. This study, terminated in 1966 after the development of a workable prototype system, demonstrated that an AVM could be built and would be satisfactory for gaging the flow in streams subject to variable backwater. 
Parallel but independent development of a working system by Westinghouse was demonstrated by tests made at the Oahe Dam and powerplant near Pierre, S. Dak。, November 3, 1964. That system showed promise of overcoming many of the operating problems still plaguing the U。S. Geological Survey system, and the availability of at least one proven commercial-grade system provided additional support for the decision to install an AVM at The Dalles site. This decision was formalized in September 1965 .

In November 1965, inspection of the proposed site at The Dalles led to the discovery of a United Telephone Co. of the Northwest submarine cable that was scheduled for abandonment early in 1966. This cable, crossing the river at the site, was tested and proved to be a suitable transmission link for the proposed AVM system. Purchase of the cable at salvage value was subsequently arranged.

The invitation for bid to acquire an AVM system for use at The Da1les site was issued in February 1967. The contract was awarded to the Westinghouse Electric Corp. in April 1967.

Acquisition of real estate was completed in May 1967. Construction of shelters and overhead transmission lines and driving of pilings for support of transducers were accomplished by mid-October 1967. The transducers were installed on October 24, 1967. Installation of electronic components was started December 4, 1967, and completed January 20, 1968, after a brief hiatus during the Christmas period. The original system had an acoustic path 1,812 feet long crossing the river at an angle of about $45^{\circ}$. Elevation of this path was 60 feet above mean sea level, about 15 feet below normal water surface.

The interface equipment required to couple the AVM system with the telephone company teletype equipment was installed June 10, 1968. Continuous record of output from the system was not available until after that date, but photographic recordings of the velocity-index display were made February 1-27 and April 12-27, 1968. During the first period, operation apparently was quite good. The correlation of daily discharges computed from the AVM and corresponding daily project figures was within a spread of +1.8 to -1.9 percent. A wider range, +17.1 to -7.2 percent, was found between AVM hourly figures and corresponding project hourly figures.

The system started to malfunction on April 16, 1968, roughly coincident with the reduction in river discharge from 145,000 cfs to an instantaneous value of 12,000 cfs during the initial filling of John Day Reservoir. Analysis showed that most of the data were obviously in error; however, only 0.6 percent of the record was flagged as faulty. System failure was probably related to changes in the river environment and the effects of these changes on the propagation of acoustic signals. However, the malfunctions continued after the filling of John Day Reservoir indicating that the system failure was not related uniquely to lowflow periods. 
Oscilloscope traces of acoustic transmissions made in early June showed large-scale fluctuations in signal strength. At times, the signal would fade out completely; at other times, the initial wave front might fade out but would be followed by a fairly strong secondary front, presumably a reflected wave traveling a longer path from transducer to riverbed and thence to the point of reception.

Realinement of the transducers resulted in some improvement, but frequent periods of no record or obviously erroneous record persisted. Because various modifications of circuitry made by Westinghouse personnel in July and October 1968 did not improve the system's reliability, an extended field surveillance was made by Westinghouse engineers in January 1969. Their conclusion, based on this period of observation and analysis of other data, was that loss of signal was due to bending (refraction) of the acoustic beam in response to very small thermal gradients in the river. Correlation between system outages and cold weather could be shown, lending support to this theory. The recommendation of the company was that the transducers be lowered and that the path length be shortened. It was theorized that smaller temperature gradients would be found midway in the vertical column and that shortening the path length would provide further security against signal loss.

Relocation of the transducers was completed on April 18, 1969 , and final system modifications and tuneup were completed on Apri1 22, 1969. Operation of the system in its final configuration relies on an acoustic path 1,320 feet long between transducers at an elevation of 38 feet above mean sea level. This places the acoustic path about 0.4 of the depth below water surface across most of the channel. Relocation of the transducers was a major undertaking involving movement of a piledriver to the site, driving and cutting of the two heavy steel piles, laying of several hundred feet of cable and rigid conduit, and final installation and alinement of the transducers.

A significant improvement in the operating stability of the system resulted from relocation of the transducers and accompanying modifications of the electronics. Records from April 22 to September 30 , 1969, had only three periods of outage in excess of 45 minutes. An outage of 4 hours occurred on June 15, 3-3/4 hours were lost on July 20, and a longer outage, 7 hours, occurred on August 24. Cause for these outages is not known, but some of the failures may have resulted from intermittent malfunction of components in the central console which have subsequently been replaced.

\section{CALIBRATION OF THE SYSTEM}

\section{Calibration Equations}

Output data from the AVM system are the velocity-index number (I) and the river stage $(H)$, which are recorded at the end of each sampling interva1--usually a 15-minute period. The velocity-index number is directly proportional to $\mathrm{V}_{\mathrm{P}}$, the average velocity parallel to the acoustic path and represents the average of $V_{P}$ during the sampling period. It is assumed that the stage, the instantaneous value recorded 
at the end of each sampling period, is steady during the sampling period and can be used as a valid index of the cross-sectional area. Errors introduced by this assumption are small and compensating.

Discharge computation can be made from these data by applying the basic equation of flow and definition of its parameters as follows.

The basic equation of flow is:

$$
Q=\bar{V} A
$$

where $Q$ is the discharge, in cubic feet per second,

$\bar{V}$ is the mean velocity in the cross section, in feet per second, and

$A$ is the area of the cross section, in square feet.

Referring to figure 11 , the relation between $\bar{V}$ and the velocity index $I$ can be summarized in the following equations:

If $\mathrm{V}_{\mathrm{P}}$ is the velocity parallel to path $\mathrm{AC}$ then

$$
\mathrm{V}_{\mathrm{L}}=\frac{\mathrm{V}_{\mathrm{P}}}{\operatorname{Cos} \theta}
$$

and as

$$
\begin{aligned}
& V_{P}=C_{1} I \\
& V_{L}=\frac{C_{1}}{\cos \theta}
\end{aligned}
$$

where $V_{L}$ is the average water velocity at the elevation of the acoustic path, in feet per second,

$\mathrm{C}_{1}$ is the constant of proportionality between $V_{P}$ and $I$, and

$\theta$ is the acute angle between the streamline of flow and the acoustic path.

Previous discussion has shown $V_{L}$ to be a stable index of $\bar{V}$, the mean velocity in the cross section. The relation between $V_{\mathrm{L}}$ and $\bar{V}$ can be expected to vary with stage because $V_{L}$ is a measure of the mean velocity along a line at a fixed elevation in the cross section. As the stage rises, the position of this line is moved downward in the cross section relative to the total depth, and resultant changes in the velocity distribution in the vertical column cause a change in the ratio between $V_{L}$ and $\bar{V}$. Correlation of the ratio $\frac{V_{L}}{\bar{V}}$ with stage is accordingly necessary, and $\bar{V}$ can be expressed as $C_{2} V_{L}$ where $C_{2}$ is a function of stage. The basic equation (11) can therefore be rewritten as

$$
Q=I\left(\frac{C_{1} C_{2}}{\operatorname{Cos} \theta}\right) A
$$

where $\mathrm{C}_{2}$ and $\mathrm{A}$ are separate functions of stage. 
Because $\frac{C_{1}}{\operatorname{Cos} \theta}$ is a constant for the system, a further simplification can be made to

$$
\mathrm{Q}=\mathrm{K} \mathrm{IA}
$$

The coefficient $\mathrm{K}$ in equation 15 combines $C_{1}$, the proportionality constant between $I$ and $V_{L}$, the factor $\frac{1}{\operatorname{Cos} \theta}$ which is the correction for the diagonal placement of the acoustic path, and the coefficient $\mathrm{C}_{2}$ which is variable with stage. This coefficient is referred to hereafter as the index-mean velocity coefficient.

Calibration of the system thus requires empirical definition of the two parameters $\mathrm{K}$ and $\mathrm{A}$ by correlation of recorded AVM output records with corresponding known discharges, cross-sectional areas, velocityindex numbers and stage data.

\section{Definition of the Relation Between Stage and Area}

Definition of area, A, as a function of stage is a straightforward empirical procedure involving only the plotting of areas computed from the measured geometry of the cross section against corresponding elevations of the water surface as shown in figure 25. This curve was developed by plotting area versus stage data from 20 current-meter measurements made at the site during the period December 12, 1967, to August 13, 1969. The standard deviation of the departures of measured areas from this curve is 0.83 percent, and only three of the measurements plot more than 1 percent from the curve. Because the banks of the section are nearly vertical, the curve developed has only a slight curvature. This curve was reduced to a straight-1ine equation and a look-up table for use in subsequent computations.

\section{Definition of the Relation Between Stage and Index-Mean Velocity Coefficient}

Definition of the relation between the index-mean velocity coefficient, $\mathrm{K}$, and stage was accomplished by inserting time-related known values of discharge, velocity-index number, and cross-section area (from the area versus stage curve) into equation 15 and solving for $\mathrm{K}$.

Ten current-meter measurements of discharge were made after the transducers were relocated and the AVM system was operating in its final configuration. This provided only a limited sample and was considered to be inadequate for thorough calibration because only a sma11 proportion of the possible backwater conditions were covered. These 


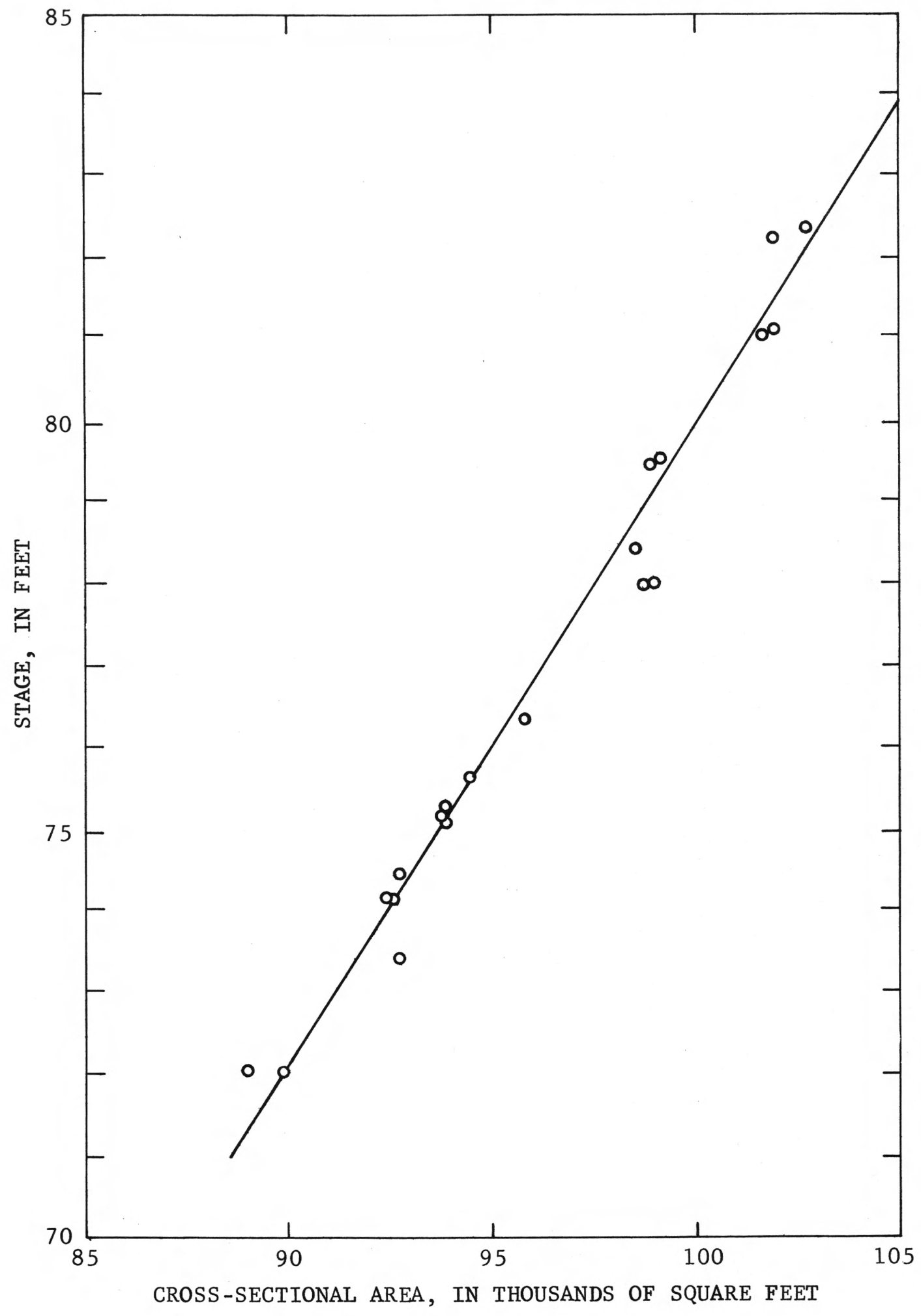

Figure 25.--Stage-area relation. 


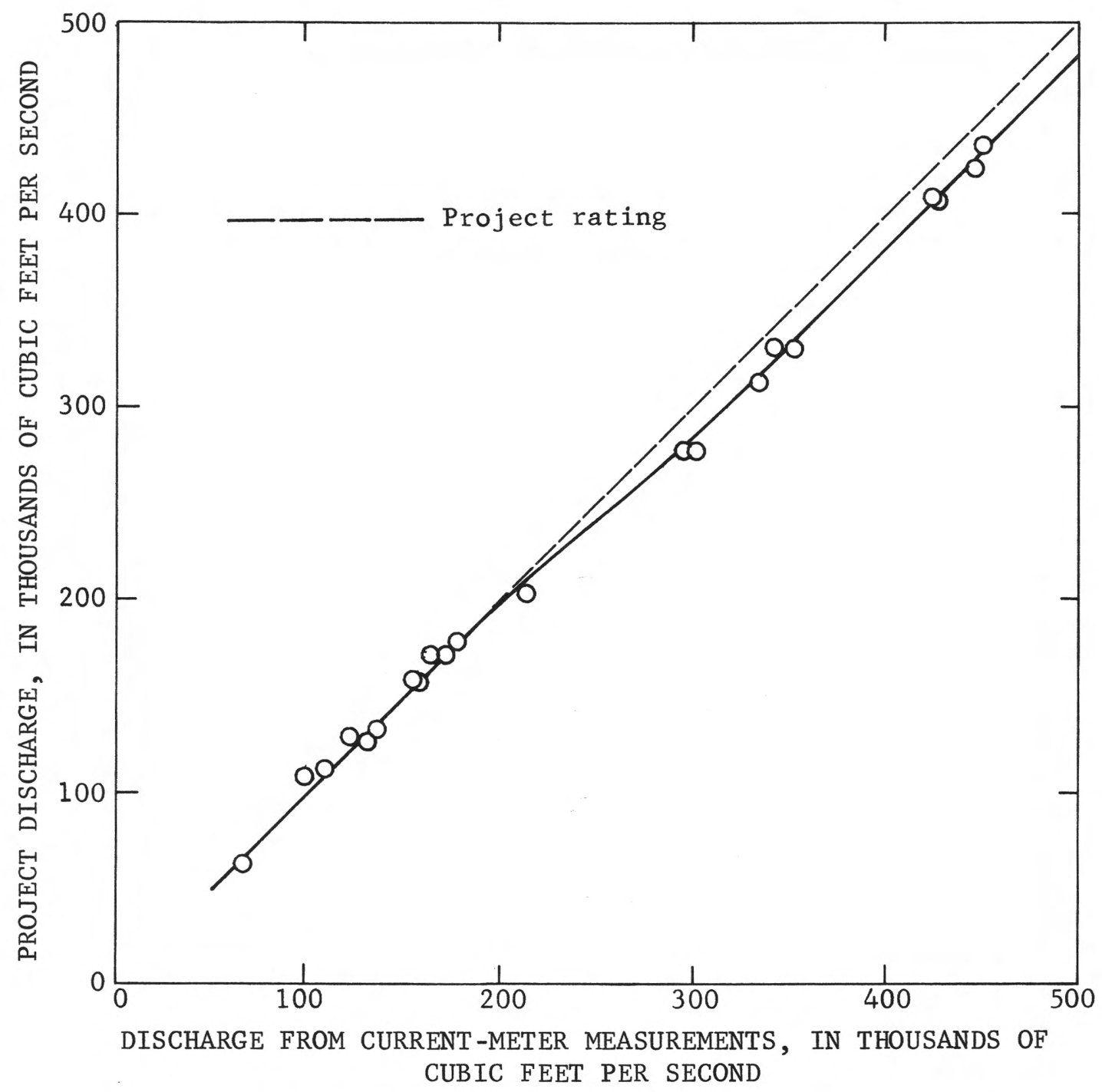

Figure 26.--Relation between project discharge and discharge from current-meter measurements.

measurements and 10 others made prior to the time the AVM system was completed were accordingly used to define a curve for adjustment of computed discharges from The Dalles project 3 miles upstream. This curve (fig. 26) was then used to adjust selected project discharges for correlation with the AVM output. A total of 117 hourly adjusted computed discharges, representing steady-flow conditions covering a range of discharge from 55,000 to 467,000 cfs, were used. These hourly data were entered, along with the corresponding average hourly velocity-index values and stage and cross-sectional areas, into a computer program for computation of the variable coefficient $\mathrm{K}$. 
These $\mathrm{K}$ values were then grouped and averaged for each foot of stage and are plotted in figure 27 along with $\mathrm{K}$ values computed from each of the 10 available current-meter measurements. The standard deviation of departures of the individual $\mathrm{K}$ values from the curve, both project discharges and current-meter measurements, is \pm 1.8 percent. Maximum departure for the current-meter measurements is 6.5 percent, and the range in departures for project discharges is from +6.1 percent to -5.0 percent.

An alternative calibration procedure, of academic interest, was performed by use of a multiple-regression analysis on the same data sets used in definition of the variable $\mathrm{K}$ function. The equation resulting from this multiple-regression analysis is:

$$
\mathrm{Q}=2.15 \mathrm{I}^{1.05} \mathrm{H}^{1.115}
$$

where $Q$ is the discharge, in cubic feet per second,

$I$ is the velocity index--a 4-digit number, and

$\mathrm{H}$ is the stage, in feet.

The standard error of estimate of the dependent variable $Q$ was +1.9 percent to -1.8 percent. Using this rating, the maximum departure of current-meter measurements from the computed AVM discharge also was 6.5 percent。

This rating, equation 16 , fits the available data as well as equation 15, but its use is not considered to be desirable. Equation 16 is a purely empirical solution which ignores the fundamental relations of the system. Equation 15 is dimensional1y correct and is based on a rational analysis of the hydraulic principles involved. The statistical approach does serve, however, to illustrate the very good correlation obtainable between discharges computed from the AVM output and those computed independently.

\section{COMPUTATION OF DAILY DISCHARGE}

Output from the AVM system is produced in two formats, the hard copy from the teletype (fig. 23), and the same data recorded in eightchannel punched paper tape. The first step in the computation procedure is the off-line translation of the punched paper-tape record onto IBM cards for input to the computer.

Discharge computations are then made by computer. Initial routines of the computer program include editing steps to eliminate or correct questionable data. Velocity-index numbers preceded by an asterisk, which denotes questionable data, are automatically eliminated from the data matrix, and mean daily computations are based on the remaining acceptable data. Equation 15, Q=KIA, is used in the basic computation routine which computes discharges for each 15-minute period by a table look-up procedure which determines the coefficient $\mathrm{K}$ and the area $\mathrm{A}$ as 


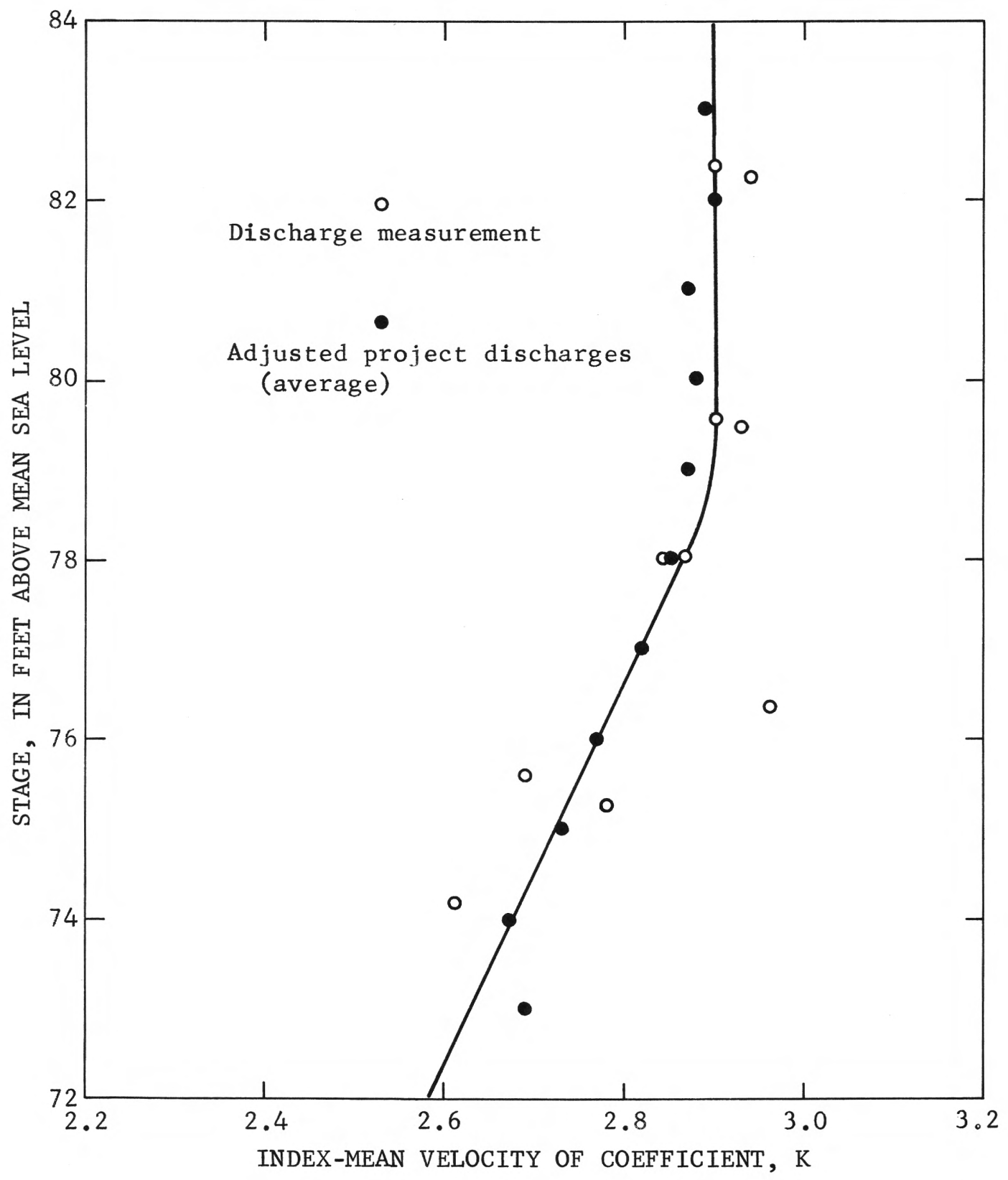

Figure 27.--Relation between stage and index-mean velocity coefficient for the AVM system with transducers located at 38-foot elevation. 
a function of the recorded stage. These values are then multiplied by I, the recorded velocity index, to determine the discharge.

The computer printout (fig. 28) 1ists the station name and number; the Julian day, that is, the sequential number of the day within the water year which begins with day 1 on October 1 ; the water year; each 15-minute and average hourly discharge; the average daily gage height; cross-sectional area, velocity, index, and mean discharge. Optional routines are included in the program to permit comparison of the daily mean discharge with project discharges and adjusted project discharges if these values are included in the input-data package. A separate printout, a graph showing comparison of individual hourly project and AVM discharges, is made if the departure between the daily mean discharge from the AVM and the adjusted daily mean project discharge is greater than 3 percent. This output is used as a final quality-control check to delineate periods when data should be manually edited.

\section{ACCURACY OF DISCHARGE RECORDS}

Rigorous statistical analysis of the error characteristics of the AVM system has not been possible because of the complex interrelation of error sources and the limited quantity of data available for analysis. Consequently, the direct comparison of corresponding AVM and project discharges yields the best insight into the probable accuracy of the AVM record.

This has been done on a daily basis and is shown in figure 29, which is the daily hydrograph of AVM discharges for the period April 22September 30, 1969. The percentage departure from adjusted project discharges is shown on the bottom line of this figure. Range in daily departures is from +3.1 percent to -3.4 percent; the standard deviation of departures is 1.29 percent, and the net departure for the period is 0.02 percent.

A similar comparison between hourly AVM and hourly project figures for the period August 1-31, 1969, showed much larger departures. The range was from +28.2 percent to -16.6 percent and the standard deviation was 4.7 percent. Departures on the order of \pm 10 percent occurred on most days. However, these extremes were almost always associated with periods of rapidly changing discharge, and their net effect on mean daily discharge was small because they tend to be compensating. The range in departures for daily discharges was from +1.9 percent to -3.1 percent for the period; and on August 19, 1969, when the maximum hour1y departure of 28.2 percent was registered, the departure between mean daily discharges was only 0.2 percent.

The AVM is located about 3 miles below The Dalles project, and significant differences in instantaneous flow can occur during nonsteady flow periods. For example, a stage change at the rate of 1 foot per hour represents approximately $7,000 \mathrm{cfs}$ going into or out of storage in the intervening reach. Correlation of instantaneous flows between these two points (the AVM site and The Dalles project) may also be affected by seiche action in the long Bonneville pool. The AVM site is at the upper end of this reach. The net effect of these factors--intervening storage 
14-1057.00 COLUMBIA RIVER AT THE DALLES, OREG.

AVM PATED DISCHARGE (USING VARIABLE COEFICIENT TABLE)

DISCHARGE IN $1000 \mathrm{CFS}$

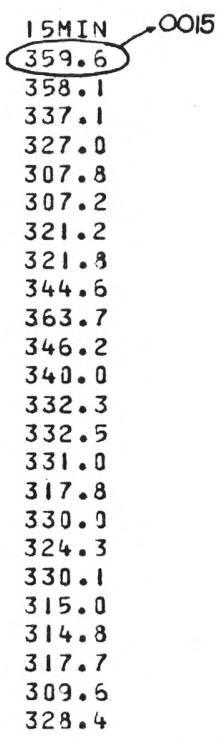

30 MIN -0030

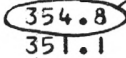

$$
336.3
$$

331.2

318.0

313.1

320.1

349.1

350.4

356.4

339.7

338.9

329.6

323.8

322.4

330.3

326.7

332.6

324.5

319.0

$324 \cdot 3$
$322 \cdot 5$

\begin{tabular}{l} 
45MIN 0045 \\
\hline 348.4 \\
350.9 \\
332.9 \\
321.3 \\
311.4 \\
312.9 \\
322.5 \\
335.9 \\
358.9 \\
345.8 \\
340.9 \\
336.0 \\
337.7 \\
324.4 \\
327.5 \\
328.6 \\
324.0 \\
328.8 \\
314.5 \\
318.3 \\
316.8 \\
318.7 \\
334.4 \\
311.9 \\
$1 \times 10.3$
\end{tabular}

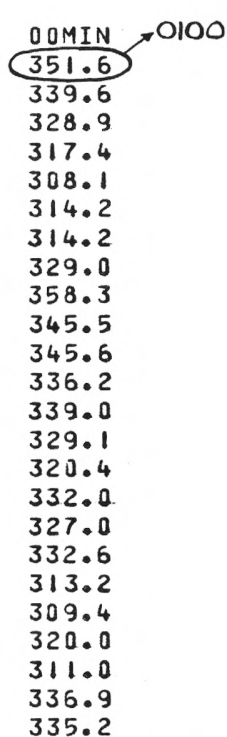

HRLY
$\begin{aligned} & 353.6 \\ & 349.7\end{aligned} \sum_{015} Q / 4$
333.8
324.2
311.3
311.8
319.5
334.0
353.1
352.9
343.1
337.9
337.0
328.9
325.7
325.2
327.8
328.1
322.6
316.8
318.2
316.6
326.3
324.5

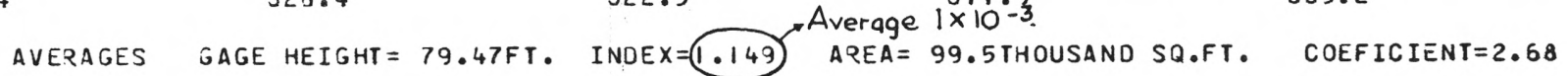
MEAN JAILY DISCHARGE = 30.DKFS (BASED ON 9615 MIN FIGURES)

MEAN DAILY DISCHARGE OF THE DALLES DAM = 306.6 KFS DAILY PERCENT DIFF. FROM DAM = 7.7 ADJUSTED MEAN DAILY OISCHARGE OF DAM $=322.6 \mathrm{KFS}$ ADJUSTED MEAN DAILY PERCENT DIFF.= 2.3 $\sum_{0015}^{2400} Q / 96$ Thousands of cubic feet per second

Figure 28.--Computer printout of discharge. 


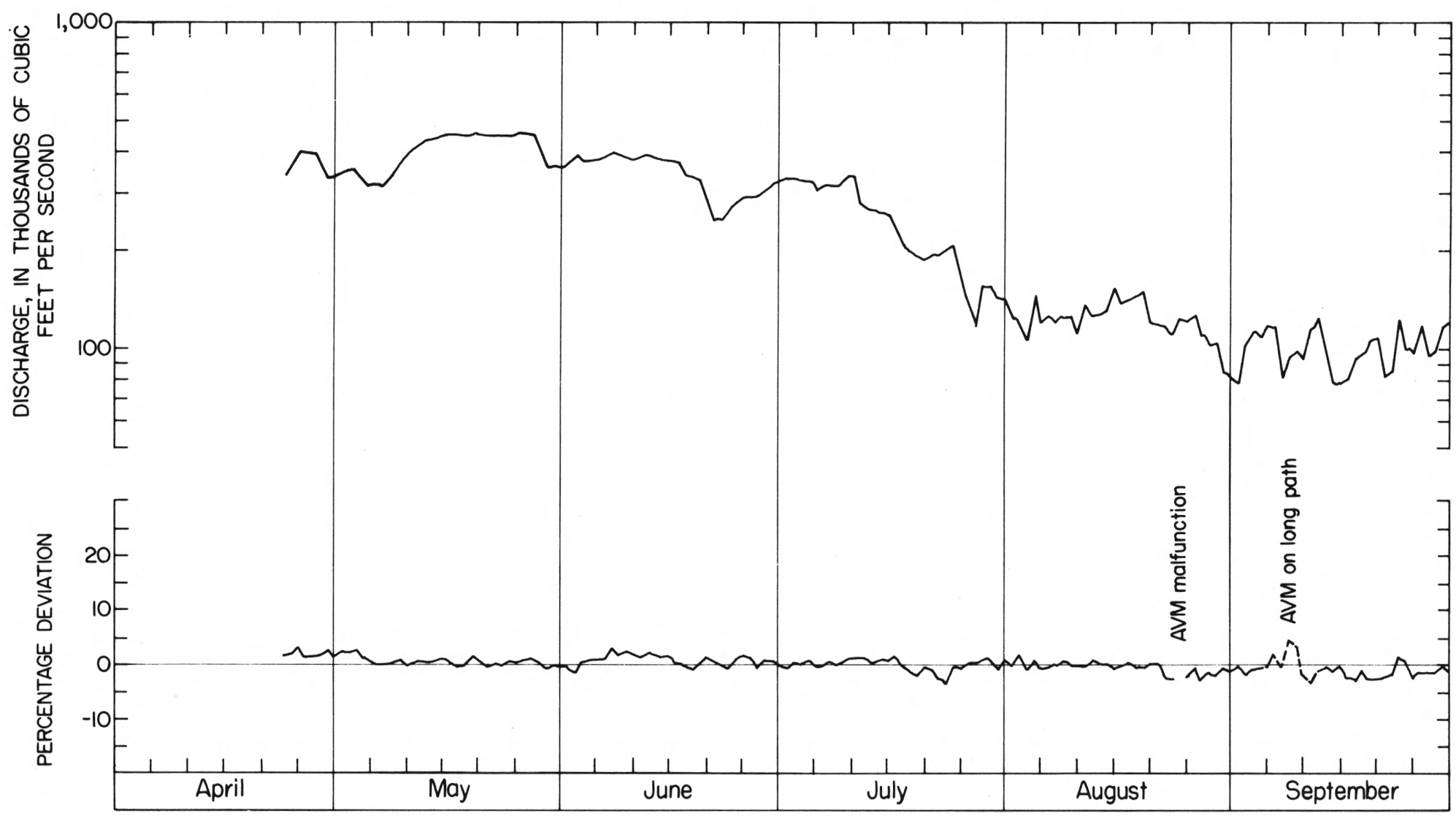

Figure 29.--Hydrograph of daily AVM discharges and graph of percentage deviation from adjusted project discharges, Apri1 22-September 30, 1969. 
and possible seiche action--is that rather large departures can be expected between instantaneous AVM and project flows, but because these effects are compensating, the departures between the mean daily flows should be sma11. Magnitude of the departures observed between hourly AVM and hourly project figures is generally within the limits of the sources noted above. Correlation between mean daily flows has been excellent, and it is safe to conclude that the AVM system is producing a reliable and consistent record. The absolute accuracy of the record is, of course, no better than that of the current-meter measurements used for the basic calibration.

\section{COSTS OF THE AVM SYSTEM AT THE DALLES}

Costs directly involved in the installation of the AVM sysiem on the Columbia River at The Dalles, Oreg., are summarized in table.2. Operation and maintenance costs are shown in table 3 .

Tab1e 2.--Cost of the AVM system at The Dalles, Oreg.

\section{Instrumentation costs}

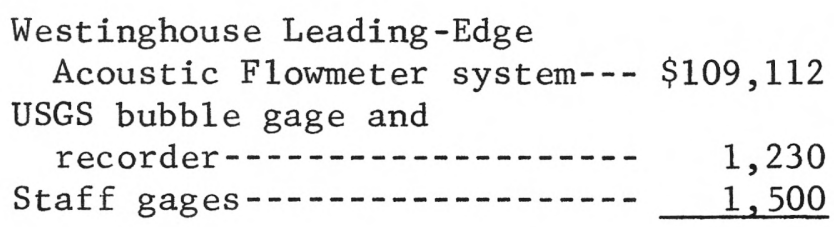

Tota1 \$111,842

Land-acquisition costs

Site survey-1,467

Purchase, fees, easements-.-- 21,817
Total \$23,284

Construction and insta11ation

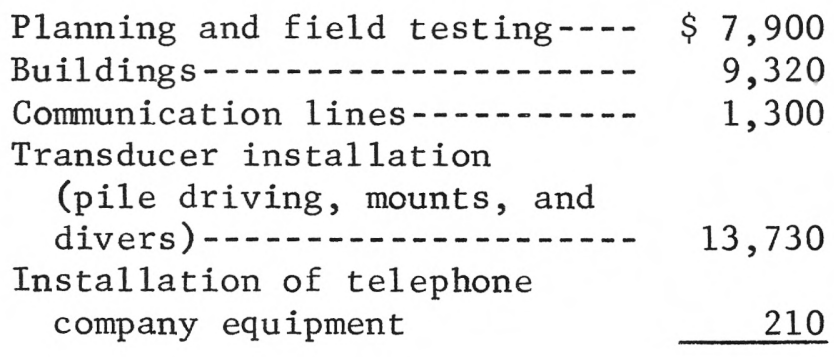

Total $\$ \underline{32,460}$

Total cost of installation- 
Table 3.--Annual operation and maintenance costs

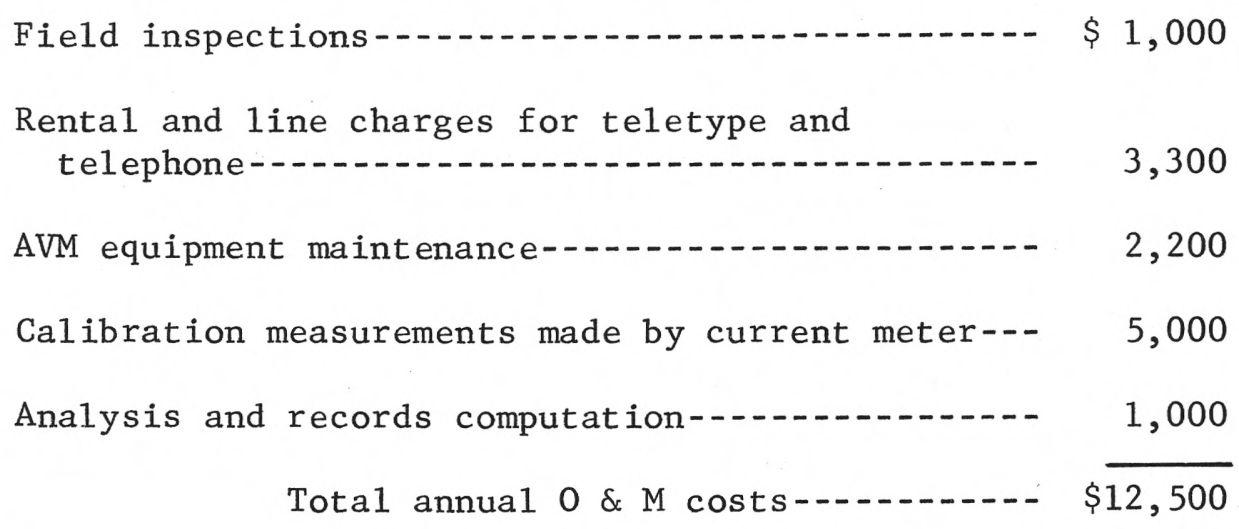

\section{DESIGN CONSIDERATIONS FOR AVM INSTALLATIONS}

An AVM system is composed of three basic subsystems: (1) a central processor that controls the operation of the system, measures the acoustic transmission times, and performs the computations necessary to convert these data into meaningful numbers, (2) a communication link intercoupling the components on the two sides of the river channel, and (3) an acoustic subsystem that includes the underwater transducers which generate and receive the acoustic signals transmitted across the acoustic path.

\section{Central Processor}

The central processor is a specialized computer programed for a specific problem. Considerations basic to the design of this unit include the velocity range of the stream to be recorded, the time interval over which integration of data is to be made, the format of the data output, and the equipment required for on-site or telemetered recording of data. Provision should be made for an internal check of the continuity of data observed so that (1) spurious data resulting from short interruptions in acoustic signal transmission do not degrade the recorded output, and (2) questionable data, resulting from longer periods of signal failure, will be flagged as erroneous output.

Developments in digital circuitry have advanced to the point where designs for such computers can be based on circuits of proven characteristics and demonstrated reliability. Consequently, this part of the system can be expected to function with a high degree of reliability and a minimum of downtime. 
To date, communication 1inks employed in AVM systems have depended on a hard-wire intertie between the two ends of the system. This seems to be the best approach and the one to be followed, if practical. However, on large channels where navigation clearances must be maintained, costs of an overhead line may be prohibitive. Utilization of a submarine cable, subject to damage by floods, may also be uneconomical due to high initial cost and short life expectancy. Therefore, use of an intertie utilizing an ultrahigh frequency or microwave 1 ink must be considered as an alternative on large rivers. This is an addition to the AVM system that imposes some complications in the AVM design and also reduces overall reliability. Economic balance of the relative cost and reliability of these various approaches--overhead lines, submarine lines, or a radio link--must be the basis for decision.

\section{The Acoustic Subsystem}

Sensitivity and operation of the AVM system are controlled primarily by the performance of the acoustic subsystem. Two factors are involved: (1) the reliability of the transmission; that is, the capability of the system to consistently transmit the acoustic signals across the selected path without interruptions due to signal 1oss, and (2) the hydraulic significance of the readout obtained which is related to the position of the acoustic path, horizontally and vertically, in the channel. These two factors are interrelated. Attenuation of acoustic transmission is a function of the characteristics of the initial pulse, the total path length, and the properties of the water in the river. Length of the acoustic path in a given channel is controlled by the diagonal position selected, and the properties of the water are influenced to some extent by the position of the path in the vertical column. The discussion that follows describes the relation between path length and the precision of velocity resolution, the significance of the angle of departure between the acoustic path and the streamlines of flow, and the signal-attenuation problem as related to changes in characteristics of the water.

\section{Relation Between Resolution Error and Path Orientation}

The basic accuracy or resolution of a given AVM system is controlled principally by the accuracy with which the arrivel times of the acoustic pulses can be discriminated and by the accuracy of the timing circuitry used to measure the elapsed times. Using the AVM system at The Dalles as an example and assuming no changes in basic circuitry for operations over paths of various orientation, the following calculation can be made. Referring to the vector relation of the system shown in figure 11,

assuming no error in $\mathrm{V}_{\mathrm{P}}$.

$$
\mathrm{V}_{\mathrm{P}}=\mathrm{V}_{\mathrm{L}} \operatorname{Cos} \theta
$$


Insertion of the resolution error $R_{e}$ yields

$$
\mathrm{V}_{\mathrm{P}}=\mathrm{V}_{\mathrm{L}} \operatorname{Cos} \theta \pm \mathrm{R}_{\mathrm{e}}
$$

or

$$
\mathrm{V}_{\mathrm{L}}=\frac{\mathrm{V}_{\mathrm{P}}}{\operatorname{Cos} \theta} \pm \frac{\mathrm{R}_{\mathrm{e}}}{\operatorname{Cos} \theta}
$$

Equation 17 shows that the net significance of the resolution error, which is fixed for a given system, is inversely proportional to the cosine of the angle between the acoustic path and the streamlines of flow and that the magnitude of the error can be computed independently from the indicated velocity.

Resolution claimed for the AVM system at The Dalles station is $+0.05 \mathrm{fps}$ for a path origina11y oriented at about $45^{\circ}$ to the channel. This implies a basic value of $\mathrm{R}_{e}= \pm 0.035 \mathrm{fps}$. Table 4 was derived by using this value of $R_{e}$.

Table 4.--Variation of resolution error with path orientation for a given AVM system

\begin{tabular}{cc}
$\begin{array}{r}\text { Path-orientation angle } \\
\text { (degrees) }\end{array}$ & $\begin{array}{c}\text { Precision of velocity resolution } \\
\text { (fps) }\end{array}$ \\
\hline 30 & \pm 0.04 \\
45 & \pm .05 \\
60 & \pm .07 \\
70 & \pm .10 \\
80 & \pm .20 \\
\hline
\end{tabular}

\section{Effects of Variation in Streamline Orientation}

If an AVM system were located a short distance downstream from the confluence of two streams, as illustrated in figure 30, then direction of the streamlines of flow past the site could be expected to vary. When flows in the tributary are low, the angle of departure between the streamlines and acoustic path will be $\theta$, but when the contribution from the tributary is high, the streamlines will shift by the angle $\emptyset$, and the departure angle will then be $(\theta+\emptyset)$.

If it is assumed for this site that velocities are uniform throughout the section and normal to the cross section, then

$$
\bar{V}=V_{L}=\frac{V_{P}}{\operatorname{Cos} \theta} \text { and } Q_{A V M}=\frac{A V_{P}}{\operatorname{Cos} \theta}
$$




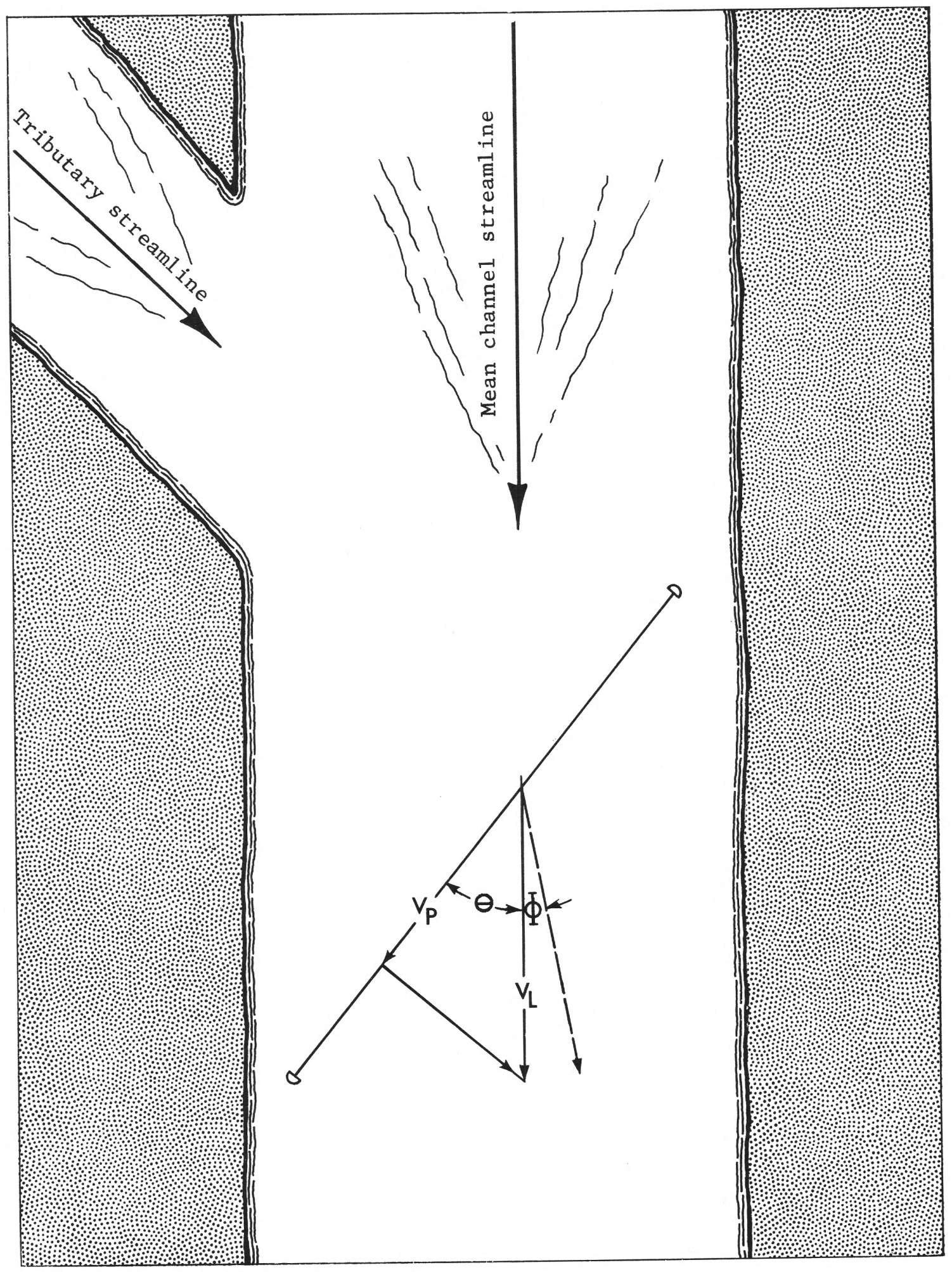

Figure 30.--Possible variation in streamline orientation. 
If the magnitude of the velocity does not change, but $\emptyset$ becomes significant by an unknown amount due to shift in the proportionate flows coming into the section, then $\bar{V}$ will no longer equal $V_{L}$ which is the velocity normal to the cross section. Thus, $\mathrm{V}_{\mathrm{L}}$ is reduced and equal to $\bar{V} \operatorname{Cos} \varnothing$, and the true discharge, $Q^{\prime}=A \bar{V} \operatorname{Cos} \emptyset$. The value of $V_{P}$ recorded by the AVM is also changed and becomes equal to $V_{P}^{\prime}=\bar{V} \operatorname{Cos}(\theta+\emptyset)$. However, QAVM, the discharge computed from the AVM data by equation 18 does not account for $\emptyset$. The computed discharge will be

$$
Q_{\mathrm{AVM}}^{\prime}=\frac{\mathrm{AV}_{\mathrm{P}}^{\prime}}{\operatorname{Cos} \theta}=\frac{\mathrm{A} \overline{\mathrm{V}} \operatorname{Cos}(\theta+\phi)}{\operatorname{Cos} \theta}
$$

The ratio between the computed and true discharges is

$$
\frac{Q_{\mathrm{AVM}}^{\prime}}{Q^{\prime}}=\frac{A \bar{V}(\operatorname{Cos} \theta+\phi) / \operatorname{Cos} \theta}{A \bar{V} \operatorname{Cos} \emptyset}
$$

which reduces to

$$
\frac{Q_{A V M}^{\prime}}{Q^{\prime}}=1-\tan \theta \tan \emptyset
$$

Equation 19 is evaluated in table 5 for acoustic path orientations $(\theta)$ ranging from $30^{\circ}$ to $60^{\circ}$ and for streamline variations $(\phi)$ ranging from $-4^{\circ}$ to $+4^{\circ}$.

Table 5.--Variation of the ratio $\frac{\mathrm{Q}^{\prime}}{\mathrm{AVM}^{\prime}}$ with $\emptyset^{\underline{1}}$

\begin{tabular}{l|rrrrrrrrrr}
\hline$\theta$ & \multicolumn{10}{c}{$\emptyset$} \\
\cline { 2 - 9 } & $-^{\circ}$ & $-3^{\circ}$ & $-2^{\circ}$ & $-1^{\circ}$ & $0^{\circ}$ & $+1^{\circ}$ & $+2^{\circ}$ & $+3^{\circ}$ & $+4^{\circ}$ \\
\hline $30^{\circ}$ & 1.040 & 1.030 & 1.020 & 1.010 & 1.000 & 0.990 & 0.980 & 0.970 & 0.960 \\
$45^{\circ}$ & 1.070 & 1.052 & 1.035 & 1.017 & 1.000 & .983 & .965 & .948 & .930 \\
$50^{\circ}$ & 1.083 & 1.062 & 1.042 & 1.021 & 1.000 & .979 & .958 & .938 & .917 \\
$60^{\circ}$ & 1.121 & 1.091 & 1.060 & 1.030 & 1.000 & .970 & .940 & .909 & .879 \\
\hline
\end{tabular}

1/ A mistake was made in an analysis similar to this published in Water-Supply Paper 1877 (Smith, 1969), and the figures in table 5 of that report are in error. 
The relation between the index-mean velocity coefficient, $K$, and river stage is significantly affected by the elevation at which the acoustic path is placed. This was demonstrated by the difference in relations defined before and after the change in transducer locations at The Dalles. No significant variation of $\mathrm{K}$ with stage was indicated by data obtained during the period of initial operation of the system when transducers were located about 15 feet below the water surface at an elevation 60 feet above mean sea level. A curvilinear relation between $\mathrm{K}$ and stage (fig. 27) was defined by data obtained after the transducers were lowered to an elevation 38 feet above mean sea level.

This observed difference in the character of the relation is in agreement with a theoretical analysis of velocity profiles which showed that the curve of $K$ versus stage was steeper when the acoustic path was placed near the surface than when the path was located deep in the cross section. The variability in the relation is, however, of no real significance; there is no theoretical reason to expect greater stability in the relation at any particular point in the vertical. Output from a system relying on acoustic signal transmission over a path deep in the water column can be as readily calibrated as that for a system operating with a path near the surface. Hence, considerations other than the hydraulic relations can be allowed to dictate the vertical location of the acoustic path.

\section{Acoustic-Signa1 Propagation}

Experience with the AVM installation at The Dalles has shown that careful consideration must be given the factors that govern the propagation of the acoustic signal through the water. These factors include the length of the acoustic path, temperature variations in the river that may cause refraction of the acoustic beam away from the selected path, and attenuation of the signal due to the presence of suspended sediment.

Refraction of acoustic signals.--Westinghouse engineers have theorized that temperature gradients in the river perhaps as low as $0.01^{\circ} \mathrm{C}$ per foot of depth were responsible for the periodic loss of signal at The Dalles when the transducers were located at an elevation of 60 feet. The acoustic path was then at a nominal depth of about 15 feet below the water surface where the effects of changes in solar radiation and air temperatures could conceivably develop small but significant temperature gradients in the water column. It is reasoned that location of the acoustic path near the mid-depth of the stream should minimize temperature gradients caused by variations in surface temperatures or heat exchange between the water and the channel perimeter.

Calculations by Westinghouse Electric Corp., based on the performance of systems at The Dalles and at other locations, led to the development of the criteria curves shown in figure 31. 


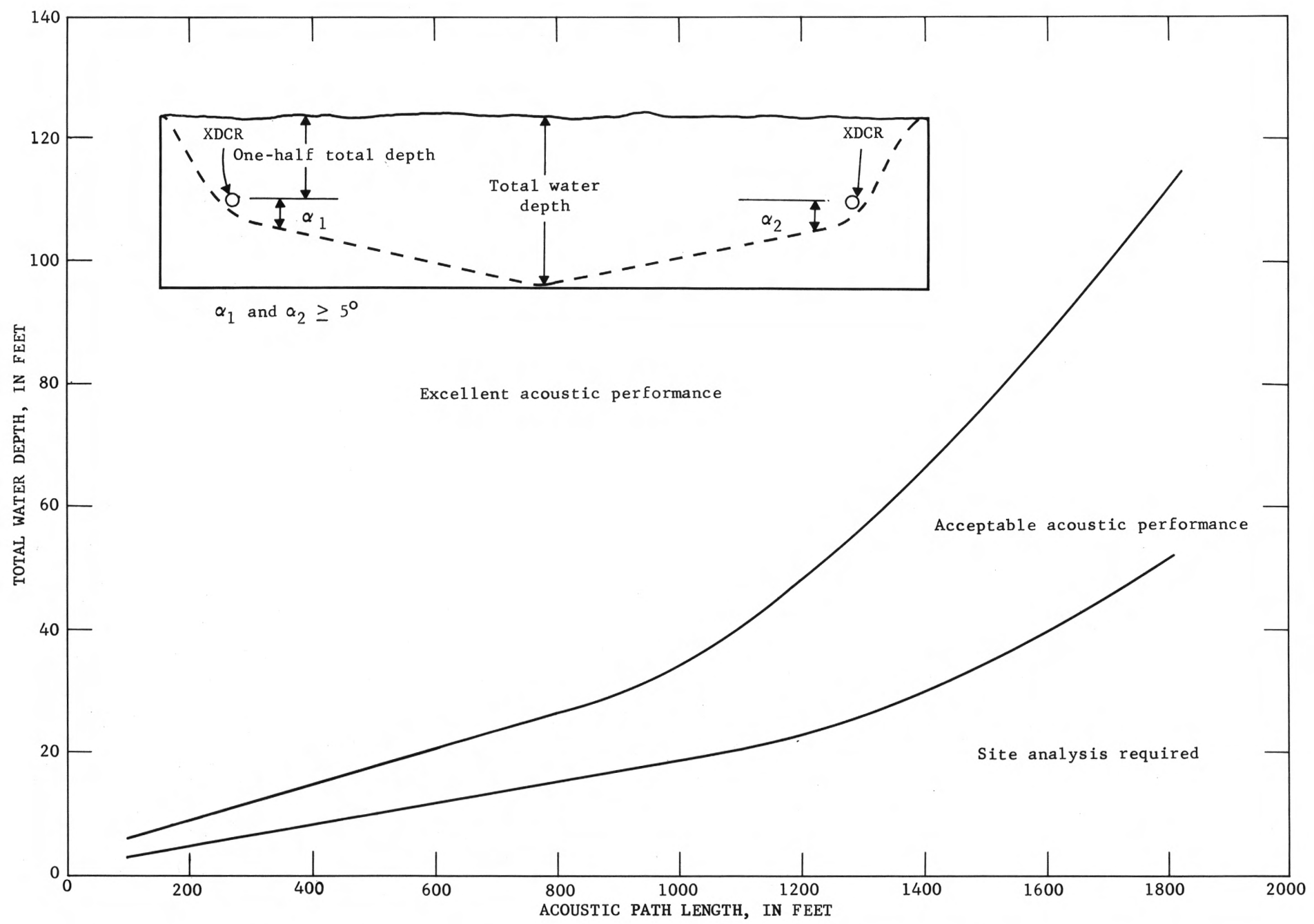

Figure 31.--Curves used as preliminary guide for AVM site selection (refraction consideration only). 
These curves are based on consideration of the refraction problem only. They indicate the performance that can be expected from a Westinghouse system for a given acoustic path length as a function of total water depth. The terms "excellent" and "acceptable" are relative and their significance is dependent upon the reliability requirements at the site. The curves show that the depth of water required increases as the path length increases. For example, for a path length of 500 feet, excellent acoustic performance would be expected for depths greater than 18 feet, acceptable performance would be anticipated for depths between 10 and 18 feet, but for depths less than 10 feet, on-site investigation of the characteristics of acoustic transmission would be necessary. For a path length of 1,000 feet, these depth ranges change to 34 feet or more for excellent transmission, from 13 to 34 feet for acceptable transmission, and on-site studies would be required for depths less than 19 feet. The curves in figure 31 should not be construed as providing al1 the information required for assessment of the potential for utilizing an AVM system. By these criteria, broad, shallow channels would seem to be questionable sites, but it is possible that further developments in transducer design and system characteristics may provide reliable performance in such channels also.

The Columbia River just below The Dalles Dam is a very well-mixed stream. Other rivers or streams with varied sources of flow affecting temperature stratification could present a much different problem to AVM operation.

Attenuation of acoustic signa1s.--Variations in the strength of received acoustic signals can also be caused by reflection and scatter of the propagated pressure wave from entrained air bubbles or from sediment particles suspended in the stream. Excess signal strength above that required for performance in clear water must be provided to ensure system operation during periods when the propagation properties of the river are impaired. This requirement for excess signal strength is referred to here as the dynamic range of the system needed to compensate for attenuation along the acoustic path during adverse conditions.

Attenuation from air entrainment is not likely in large river channels, but significant reduction in signal strength may result from the presence of suspended sediment.

The magnitude of attenuation of signal strength from reflection and scatter of the acoustic signals from sediment particles suspended in the stream has not been fully documented. Published studies have generally been limited to attenuation losses incurred by signals in the megahertzfrequency range, and extrapolation of such data to the 100-kilohertz frequency used in the system under discussion may be questionable. However, computations based on Flammer's equation (1962), the solid 1ine in figure 32, and an independent estimate furnished by McLeroy (written commun。, 1968, U.S. Navy Mine Defense Laboratory), the dashed 1ine in this figure, serve to illustrate the possible magnitude of the attenuation of signal strength from this source. Factors involved in the computation are total suspended-sediment concentration, size distribution of the sediments, water temperature, and length of the acoustic path. Figure 32 shows the relation between attenuation, expressed in 


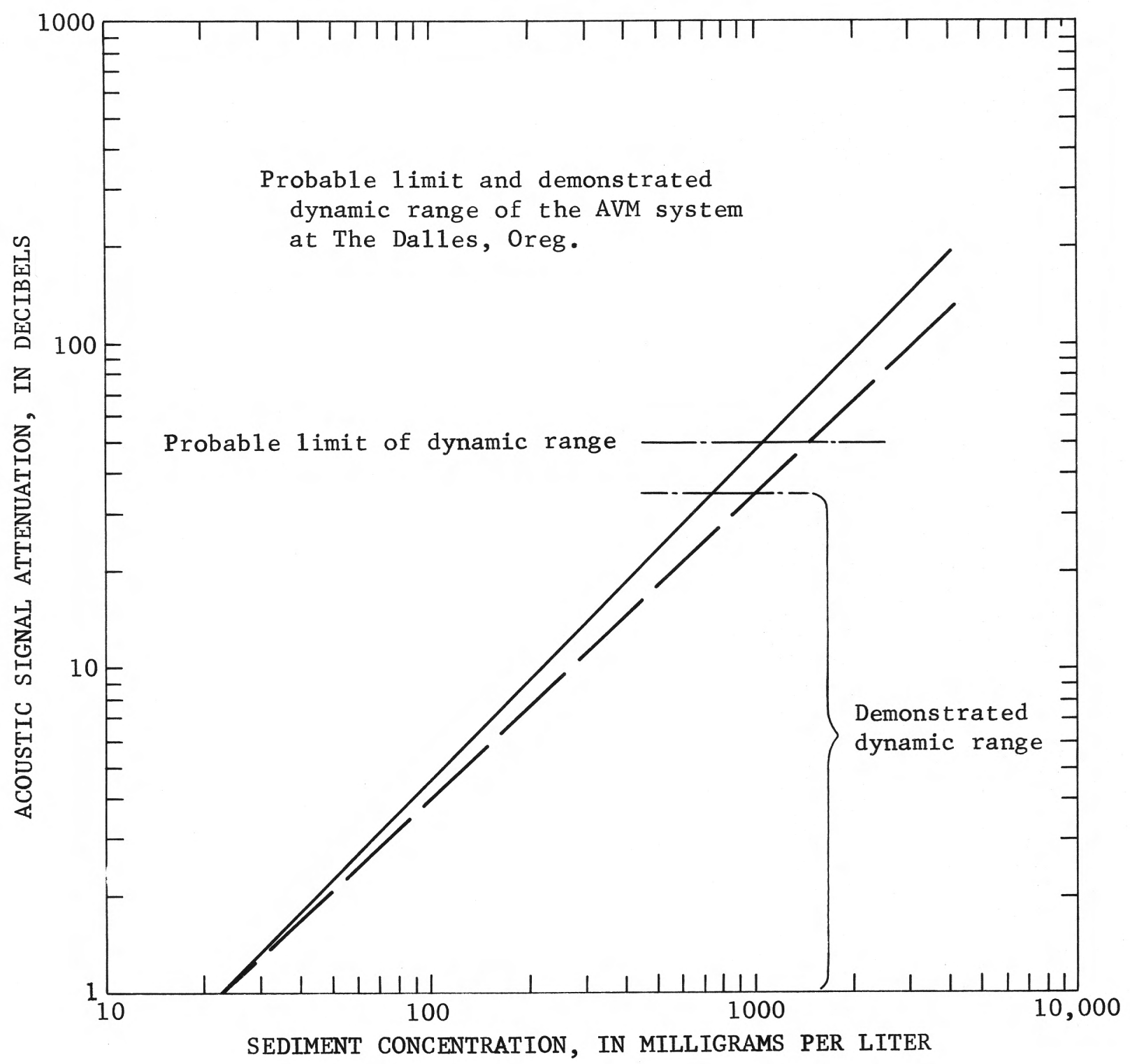

Figure 32.--Attenuation of acoustic signal caused by suspended-sediment load. 
decibe1s, and suspended-sediment loads of a size distribution considered to be typical for the Columbia River. Path length used in the computations was 1,320 feet, and water temperature was assumed to be $16^{\circ} \mathrm{C}$.

If the assumptions basic to these computations are valid, then system failure should be anticipated during periods when the sediment loads at Columbia River at The Dalles exceed $1,500 \mathrm{mg} / 1$ according to McLeroy's estimate or when they exceed $1,100 \mathrm{mg} / 1$ on the basis of Flammer's equations. At these concentrations, the attenuation indicated is 50 decibels, which is equal to the probable maximum dynamic range for the acoustic-transmission system. Duration statistics for sediment loading at The Dalles can be roughly estimated from records in the lower river. From these figures, shown in table 1, it is probable that sediment concentrations will rarely exceed $1,000 \mathrm{mg} / 1$, and then for very short periods of time. In most years sediment concentrations will not exceed $500 \mathrm{mg} / 1$, a loading which should not cause system failure.

The scarcity of data on the significance of suspended sediment in the transmission of acoustic signals points up the need for careful documentation of system performance during flood periods when sediment loads are high. Valid data are needed to establish realistic dynamicrange requirements for AVM systems.

\section{Placement of the Acoustic Path}

The foregoing discussion points up the interrelation of the factors involved in placement of the acoustic path in a given stream. The most important consideration is to ensure reliable acoustic transmission, and this leads toward selection of the shortest possible path to minimize acoustic refraction and attenuation losses. Consideration of the hydraulic aspects of the system suggests use of a long path at a steep angle of incidence to the streamlines to achieve the best resolution of velocity and to reduce the effects of variations in streamline direction. These are opposing restraints on the system configuration that will require compromises in some instances. For most installations, the desired resolution can be met by utilizing a path at the mid-depth position and at an angle of $45^{\circ}$ to the streamlines. Narrow, deep sections of a river are to be preferred over broad, shallow sections, and locations influenced by tributary inflow should be avoided. On-site investigation of acoustic-propagation characteristics will be desirable at sites where the depth-to-path-1ength criteria of figure 31 indicate possible problems. Because of excessive loss of record from signal attenuation, use of AVM systems may not be practical in streams that frequently carry large sediment loads. 
1. Conventiona1 stream-gaging procedures, dependent on correlations between river stage and measured discharges, do not meet the needs for computation of discharge records of documented accuracy in large river channels subject to variable backwater. Equipment such as the AVM system described herein is needed to permit such computations and to provide the independently produced flow records necessary for proper management in many highly developed river basins.

2. Performance of the Westinghouse Leading-Edge Acoustic Flowmeter installed at the Columbia River at The Dalles, has proven to be successful and indicates that instrumentation of this type can be utilized effectively in measuring the flow of large rivers subject to variable backwater.

3. Calibration of AVM systems can be made by current-meter measurements, and reliable documented records of flow can be obtained.

4. Criteria have been developed, on the basis of the experience at The Dalles, for evaluation of the usefulness of AVM systems at other sites. These include consideration of problems of acoustic transmission and the hydraulic characteristics of the river. 
Barron, E. G., 1963, New instruments for surface-water investigations, in Selected techniques in water-resources investigations: U.S. Geo1. Survey Water-Supp1y Paper 1669-Z, p. Z1-Z12.

Buchanan, T. J., and Somers, W. P., 1969, Discharge measurements at gaging stations: U。S. Geol. Survey Techniques Water-Resources Inv., book 3, chap。A8, 65 p。

Carter, R。Wo, and Davidian, Jacob, 1965, Discharge ratings at gaging stations: U.S. Geo1. Survey Surface Water Techniques, book 1, chap. $12,36 \mathrm{p}$.

1968, General procedure for gaging streams: U.S。Geo1. Survey Techniques Water-Resources Inv., book 3, chap. A6, 13 p.

Craig, F. C。, 1963, Variation in velocity distribution in a tideaffected stream, in Selected techniques in water-resources investigations: U.S 。Geol. Survey Water-Supply Paper 1669-Z, p. Z17-Z24.

Flammer, G. H., 1962, U1trasonic measurement of suspended sediment: U.S. Geo1. Survey Bu11. 1141-A, 48 p.

Miller, E. G., 1962, Observations of tidal flow in the Delaware River: U.S. Geo1. Survey Water-Supply Paper 1586-C, 26 p.

Smith, Winche11, 1969, Feasibility study of the use of the acoustic velocity meter for measurement of net outflow from the SacramentoSan Joaquin Delta in California: U.S. Geol. Survey Water-Supply Paper 1877,54 p.

Smith, Winche11, and Wires, H。 O。, 1967, The acoustic velocity meter-A report on system development and testing: U.S. Geo1. Survey open-file rept., $43 \mathrm{p}$.

U.S. Geologica1 Survey, 1949, Large rivers of the United States: U.S. Geo1. Survey Circ. 44, 5 p. 
A Area of cross section, in square feet (a function of stage)。

B Length of acoustic path from A to C, in feet.

$\mathrm{C}_{1} \quad$ Constant of proportionality between $\mathrm{V}_{\mathrm{P}}$ and $\mathrm{I}$.

$\mathrm{C}_{2} \quad$ A function of stage proportional to $\mathrm{V}_{\mathrm{P}}$ and $\mathrm{I}$.

c Propagation rate of sound in still water, in feet per second.

$\mathrm{H} \quad$ River stage, in feet.

I Velocity-index number from AVM system.

K Index-mean velocity coefficient.

Q Discharge, in cubic feet per second.

$\mathrm{Q}_{\mathrm{AVM}}$ Discharge computed from AVM index and stage, in cubic feet per second.

$\mathrm{R}_{\mathrm{e}} \quad$ Resolution error, dependent on path angle to streamlines.

$\mathrm{T}_{\mathrm{AC}}$ Trave1time, in seconds, from point $\mathrm{A}$ to point $\mathrm{C}$.

$\mathrm{T}_{\mathrm{CA}}$ Traveltime, in seconds, from point $\mathrm{C}$ to point $\mathrm{A}$.

$\Delta \mathrm{T} \quad$ Difference in traveltime, $\left(\mathrm{T}_{\mathrm{AC}}{ }^{-\mathrm{T}} \mathrm{CA}\right)$, in seconds.

$\overline{\mathrm{V}} \quad$ Average water velocity, in feet per second.

$\mathrm{V}_{\mathrm{L}}$ Line velocity, the average water velocity at the elevation of the acoustic path, in feet per second.

$\mathrm{V}_{\mathrm{n}} \quad$ Average component of water velocity normal to the acoustic path.

$\mathrm{V}_{\mathrm{P}} \quad$ Average component of water velocity parallel to acoustic path, in feet per second.

$\theta \quad$ Angle of departure, in degrees.

$\emptyset \quad$ Change in angle of departure, in degrees. 


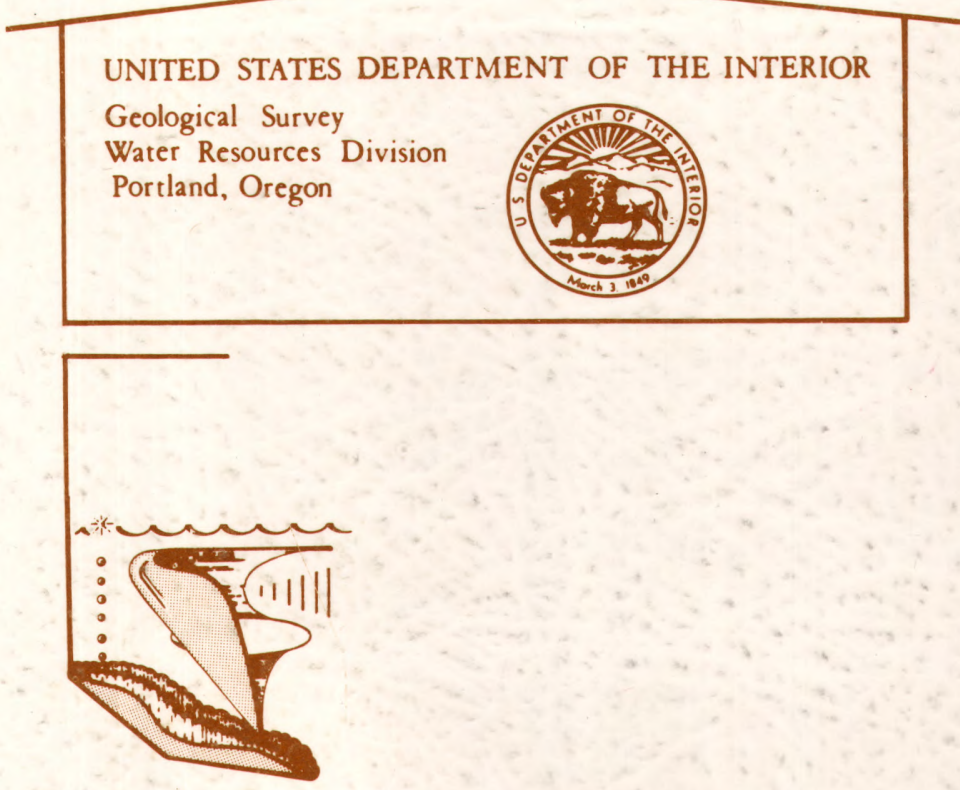